\title{
Motivation, pedagogy, and gender: examining the multifaceted and dynamic situational responses of women and men in college STEM courses
}

\author{
Jonathan D. Stolk*iD, Michael D. Gross ${ }^{2}$ and Yevgeniya V. Zastavker ${ }^{1}$
}

\begin{abstract}
Background: Research illustrates that student motivations influence learning engagement, persistence, and achievement in powerful ways and that positive motivations are linked to deeper learning, critical thinking, prosocial behavior, and better performance. Most studies of learner motivation, however, are conducted outside of STEM and are focused at the contextual level, which may describe why students attend college or choose a degree program, but not why they engage in classroom activities. Furthermore, there is little research that meaningfully connects learner motivations with gender identity and course pedagogy. This study addresses these gaps by examining the interconnections among course pedagogy, gender, and situational-level motivations, which reveal why learners engage in different course activities and how engagement may vary over time. This detailed perspective on learner motivations is essential for instructors to gain insights into how their pedagogical and course design choices influence students' motivational responses and to more effectively develop interventions that support positive forms of motivation among all students.

Results: Participants in the study are undergraduate students enrolled in 72 introductory-level STEM courses across 11 institutions, and the dataset includes over 5000 unique responses to the Situational Motivation Scale, a SelfDetermination Theory-based instrument that was administered weekly in each course. Analysis reveals seven typical motivational response types, ranging from a highly control-oriented to a highly autonomous response. Most students express multiple types of motivation during an academic term in a course, illustrating the dynamic nature of motivations. Cluster distributions by gender and pedagogy indicate significant differences in lecture-based learning courses, with women reporting less self-determined motivations compared to men. Motivational response profiles of women and men are both more similar, and more positive overall, in courses that employ active learning.

Conclusions: These findings have important implications for practitioners. The concept of motivational co-expression encourages instructors to move toward a more nuanced appraisal of learner motivation. The stability analyses challenge embedded beliefs about the fixed nature of learner motivation. The gender analyses raise questions about how instructors may more effectively promote the positive motivations of all students through their course design decisions.
\end{abstract}

Keywords: Motivation, Gender, Pedagogy, Self-determination theory, Motivational dynamics, Active learning, STEM

\footnotetext{
*Correspondence: stolk@olin.edu

'Olin College of Engineering, 1000 Olin Way, Needham, MA 02492, USA

Full list of author information is available at the end of the article
}

\section{Springer Open}

(c) The Author(s). 2021 Open Access This article is licensed under a Creative Commons Attribution 4.0 International License, which permits use, sharing, adaptation, distribution and reproduction in any medium or format, as long as you give appropriate credit to the original author(s) and the source, provide a link to the Creative Commons licence, and indicate if changes were made. The images or other third party material in this article are included in the article's Creative Commons licence, unless indicated otherwise in a credit line to the material. If material is not included in the article's Creative Commons licence and your intended use is not permitted by statutory regulation or exceeds the permitted use, you will need to obtain permission directly from the copyright holder. To view a copy of this licence, visit http://creativecommons.org/licenses/by/4.0/. 


\section{Introduction}

Instructors tend to oversimplify learner motivations in the classroom, by labeling students or even entire groups of students as simply "motivated" or "unmotivated," or by making generalized assumptions about what drives students to learn, e.g., my students only care about grades. Studies of learner motivation in educational settings show, however, that motivation is not a binary trait-based variable. Rather, it is a complex and dynamic response, shaped by personal, interpersonal, and contextual factors.

Educational research illustrates that learner motivations are influenced in powerful ways by instructors' pedagogical and behavioral choices (Garcia and Pintrich 1996; León et al. 2015; Noels et al. 1999; Patall et al. 2008; Reeve 2009; Reeve et al. 2004). Different classroom situations give rise to different types of learner motivation, and these particular types of motivations shape students' engagement, persistence, and achievement (Deci and Ryan 2000; Pelletier et al. 2001; Pintrich 1999; Ratelle et al. 2007). Positive forms of motivation, such as value- or interest-based drive, are linked to deeper learning approaches, better performance, and outcomes such as critical thinking, pro-social behavior, and selfregulation (Deci and Ryan 2000; Gagné 2003; Pintrich 1999; Pintrich and De Groot 1990). By contrast, less positive motivations, such as reward-based drive, relate to surface-level learning, poorer performance and persistence, and negative emotions (Black and Deci 2000; Deci and Ryan 2000). These relationships are not simply correlational: path models illustrate causal links between different types of motivations and specific learning outcomes (Fortier et al. 1995; Kaplan and Madjar 2017; Lavasani et al. 2011; Walker et al. 2006). Given the impacts of course design on motivation and the effects of motivation on outcomes, educational practitioners may benefit from a detailed perspective on learner motivations that illustrates the relationships between pedagogical choices and motivations at the situational or class activity level, where opportunities for interventions may be more apparent and more easily understood.

This study adds depth and nuance to educators' understanding of student motivation in college STEM courses by presenting findings from quantitative cluster analysis of situational motivations, a technique that reveals the multifaceted nature of motivation, or learners' simultaneous expression of different forms of motivation at any given time (Ratelle et al. 2007). In addition, we examine relationships among motivation, pedagogy, and self-reported gender identity and assess the stability of students' motivations throughout the semester in a course. Enhancing the educational community's understanding of how women and men motivationally engage in STEM learning is especially important at this time, as
STEM is not succeeding in creating diverse and inclusive learning environments. Indeed, the billions of dollars spent on initiatives aimed at increasing the percentage of women and other underrepresented groups in STEM (National Science and Technology Council 2011) have resulted in little gain over the past 20 years. Despite the rise in the total number of science, technology, engineering, and mathematics (STEM) degrees awarded in the USA, the share of degrees earned by women in STEM fields remained essentially constant at 35\% between 2008 and 2016 (U.S. Department of Education 2018). Examining STEM through a student motivation lens may provide valuable insights into this challenge.

\section{Literature review and theoretical framework}

This study takes a Self-Determination Theory (SDT)based approach to learner motivation (Deci et al. 1991; Deci and Ryan 2000; Ryan and Deci 2000). A central concept of SDT is that there are different types of motivation that may be described along a continuum that ranges from internal (autonomous) to external (controlled) motivations (Ryan and Deci 2000). At one extreme is intrinsic motivation, a state described by interest, enjoyment, inherent satisfaction, and personally valuable goals. At the other extreme of the continuum is amotivation, a condition that occurs when learners find no value in the learning activity and expect no desirable outcomes. Between the two extremes lies extrinsic motivation, a state in which initiative and regulation of action may be prompted by a range of inputs, from external rewards and punishments (external regulation) to an identification of value in the learning activity (identified regulation). The SDTdefined types of motivation considered in this study are summarized in Table 1. Not all types of motivation are equally effective for learning. In general, internalized motivations bear positive relationships to desirable learning outcomes and healthier engagement with learning, while externalized motivations do not (Deci et al. 1999; Fortier et al. 1995; Pelletier et al. 2001; Vansteenkiste et al. 2006; Vansteenkiste et al. 2009).

As a need-based motivation theory, SDT argues that individuals will adopt internalized, or autonomous, motivations when three basic needs are satisfied: competence, the development of a sense of mastery or self-efficacy; relatedness, a sense of positive and supportive connections to others; and autonomy, a sense of choice and control (Deci and Ryan 2000). Addressing these needs in the classroom enables students to more easily internalize learning goals and shift their motivations from extrinsic to intrinsic (Deci and Ryan 2000). When students internalize learning, they see the value in these goals and gradually accept them as their own. Over time, the learning goals become part of their own identity and thus much easier to maintain and endorse (Ryan and Deci 2000). 
Table 1 Four types of motivation measured by the Situational Motivation Scale (SIMS), ordered from most self-determined (top) to least self-determined (bottom) (Ryan and Deci 2000)

\begin{tabular}{ll}
\hline Motivation type & Description \\
\hline Intrinsic motivation & Deeply internalized engagement based on interest, enjoyment, satisfaction, or passion in an activity \\
Identified regulation & $\begin{array}{l}\text { Internal drive that is congruent with an internal sense of self, and based on perceived value, importance, or usefulness } \\
\text { of a task } \\
\text { External regulation }\end{array}$ \\
Amotivation & $\begin{array}{l}\text { Impersonal or non-intentional action described by perceived lack of control and a disconnection between actions and } \\
\text { outcomes }\end{array}$
\end{tabular}

\section{Situational motivations}

To distinguish between short-term and long-term motivational responses, SDT researchers use the hierarchical model of motivation (Guay et al. 2003; Vallerand 2000), which describes motivations at three categories of generality: global, contextual, and situational. Global levels of motivation are abstract orientations individuals perceive to be part of their personal beliefs and identity. Contextual levels of motivation describe a person's perceived relationship to domains such as "school," "sports," or "my major." The situational level describes motivational responses to a particular activity, such as a course assignment or teaming interaction. Research indicates that all levels of motivation can change over time and that the three levels interact in a reciprocal (top-down and bottom-up) manner (Corpus et al. 2009; Guay et al. 2003; Lavigne and Vallerand 2010; Ratelle et al. 2005). That is, the way an individual approaches school and learning in general can affect the way he or she approaches new learning activities or environments. Conversely, specific course activities will, over time, influence the students' more general feelings toward learning. Importantly, these interactions may operate both for better and for worse. This study focuses on situational level motivations as a classroom-level response that educators may readily influence through their day-to-day and week-to-week decisions about course activities, instructional practices, and student interactions.

\section{Motivation as a complex and dynamic response}

Real-world motivational responses are more complex than the distinct categories along the self-determination continuum may imply (Table 1). SDT-based studies show that motivation types do not exist in isolation and that the different types of motivation are not mutually exclusive. Rather, individuals simultaneously express multiple forms of motivation in a given activity (Boiché et al. 2008; Dillon and Stolk 2012; Gillet et al. 2017; Hayenga and Corpus 2010; Ratelle et al. 2007), e.g., a student may engage to attain a good grade and find value and interest in the learning. While the research on learners' simultaneous expression of different situational motivations is limited, the findings indicate that considering the "quality" of motivations with a multidimensional characterization can provide a more accurate and insightful understanding of learner drive.

In theory, situational motivations are short-term, dynamic responses that are influenced by personal and contextual variables and shaped by students' appraisals and interpretations of the learning experience (Corpus and Wormington 2014; Deci and Ryan 2000; Garcia and Pintrich 1996; Lavigne and Vallerand 2010; Ratelle et al. 2005; Skinner and Belmont 1993; Young 2005). Individuals are certainly not limited to either autonomous or controlled motivations; they may move toward more or less internalized forms of drive during the learning process (Dillon and Stolk 2012; Rotgans and Schmidt 2011). As such, measured situational motivations are expected to show fluctuations that reflect a student's reactions to a learning task, activity, or environmental cues (Boiché et al. 2008). The empirical research on situational motivational dynamics, however, is quite limited; and the published findings are mixed. For example, Rotgans and Schmidt (2011) illustrate that students' situational interest may vary over time as students progress through a learning experience. In their studies of situational motivations, Dillon and Stolk (2012, 2014) show that students may express dynamic situational motivations throughout the semester in STEM classrooms and that these intra-semester motivational shifts are not always apparent with pretest-posttest motivation measures. In contrast, Gillet et al.'s (2017) analysis of firstyear college students' motivations shows "moderately stable" to "very stable" expression of motivations over time. Despite the mixed findings reported in the literature, the concept of dynamic motivations rings true with instructors who have observed sudden shifts, or ebbs and flows, of group and individual motivations during a course. This study quantitatively characterizes the stability of individual's situational motivations to help shed light on this underexplored area of motivation research.

\section{Motivation and pedagogy}

Based on SDT, autonomous motivations and desirable learning outcomes should emerge in settings that 
promote a sense of success and progress (competence), build positive interpersonal connections (relatedness), and support choice and control (autonomy). Conversely, settings that thwart learners' basic needs should lead to controlled motivations and less desirable outcomes. Research across a range of settings clearly demonstrates the importance of autonomy support to motivation (e.g., Black and Deci 2000; Garcia and Pintrich 1996; León et al. 2015; Patall et al. 2008). In addition, intrinsic goal framing, supportive communication styles, efficacybuilding experiences, peer support, and emotional sensitivity lead to internalized forms of motivation and positive engagement (Reeve 2009; Ruzek et al. 2016; Vansteenkiste et al. 2005; Wang and Eccles 2013). On the contrary, controlling teacher behaviors have been shown to lead to negative motivation types and restricted engagement (Assor et al. 2005; Noels et al. 1999; Ratelle et al. 2005). Using path or structural equation modeling, studies have illustrated the positive influence of perceived competence and self-determination on autonomous motivations and academic performance (Fortier et al. 1995); the linkages between autonomy support and self-efficacy, mastery goals, strategy use, and achievement (Greene et al. 2004); and the connections between self-efficacy and intrinsic motivation and meaningful cognitive engagement (Walker et al. 2006).

Although empirical research that directly links different pedagogical approaches with motivation types is limited, active and student-centered pedagogies appear to be well aligned with the principles of self-determination and intrinsic motivation (Hmelo-Silver 2004). For example, Stefanou et al. (2013) reported high levels of perceived autonomy support among students in problemand project-based courses, and Stolk and Harari (2014) illustrated connections among positive motivations and high-level cognitions in project-based courses. The motivational benefits of active learning may arise from increased satisfaction of learners' basic psychological needs of competence, relatedness, and autonomy. As examples, Wijnia et al. (2011) reported higher learner competence in problem-based learning (PBL) courses compared to lecture-based learning; Liu et al. (2009) found high degrees of competence and relatedness in project settings; and Nie and Lau (2010) found higher student self-efficacy and perceived value in courses with constructivist instruction compared to didactic instruction. Trenshaw et al. (2014) reported that, compared to exams, design projects have a more positive impact on learner competence, and that relatedness serves as a key factor in promoting internalized motivations in projects. Stolk, Jacobs, et al. (2018) illustrated strong positive correlations between competence and autonomy and self-determined motivations in a project-based setting. Generally, more highly self-regulated learning (SRL) settings are shown to support more positive motivations (Paris and Paris 2001; Pintrich 1999; Pintrich and De Groot 1990). Active pedagogies do not always promote internalized motivations, however, and problem- and project-based pedagogies are sometimes implemented with structures and constraints that do not support learners' sense of self-determination. For example, in their study of undergraduate students' motivations, Wijnia et al. (2011) reported no differences between lecture and problem-based settings despite a students' higher competence in PBL-a finding that highlighted the importance of implementing an autonomy supportive rather than controlling environment, regardless of the pedagogy.

\section{Motivation and gender}

Much of the research on gender and motivation has focused on learners' self-efficacy and perceived confidence, or on learners' goals, interests, and values. Gendered patterns in learners' perceived competence and selfefficacy within gender-role stereotyped domains such as mathematics and engineering are widely reported (Schunk and Pajares 2002; Meece et al. 2006). While some studies report mixed results or no significant gender differences in self-efficacy in technical domains (e.g., Britner and Pajares 2006; Concannon and Barrow 2009; Concannon and Barrow 2010; Zimmerman and Martinez-Pons 1990), the majority of investigations show that girls or women express lower self-efficacy or perceived confidence in their technical abilities compared to boys or men, regardless of demonstrated ability or success in their programs (e.g., Besterfield-Sacre et al. 2001; Brainard and Carlin 1998; DeBacker and Nelson 2000; Gasco et al. 2014; Hackett and Betz 1989; Hutchison-Green et al. 2008; Jones et al. 2010; Marra et al. 2009; Vogt 2007; Weisgram and Bigler 2006). As with self-efficacy, the findings on gendered interests and values in STEM are mixed. Weisgram and Bigler (2006) showed that girls report less interest in science and more strongly endorse altruistic values and egalitarian interests compared to boys; and Diekman and Steinberg (2013) found that women more strongly endorse communal goals than men. In some studies, interest in or perceived value of certain STEM topics was reportedly higher among boys and men compared to girls or women (e.g., Meece et al. 2006; Trautwein and Ludtke 2009; Wigfield et al. 2002). Other studies show no gendered differences in STEM domain interests or values, even when significant gender differences in self-efficacy exist (e.g., DeBacker and Nelson 2000; Gasco et al. 2014; Greene et al. 1999; Jacobs et al. 2002; Jones et al. 2010).

While our understandings of women and men's selfefficacy, goals, and values has progressed over the past two decades, studies on the orientations or types of motivations women and men express in learning situations are quite limited. Studies that directly measure intrinsic/ 
extrinsic or autonomous/controlled motivations by gender are especially scarce, particularly at the college level. Moreover, the findings on gender and motivational orientations are mixed. Several studies showed that women reported higher autonomous motivations and lower controlled motivations compared to men (Ratelle et al. 2007; Vallerand et al. 1992; Vallerand and Bissonnette 1992). Other studies reported no gender differences in situational- or contextual-level motivations (Liu et al. 2009; Ratelle et al. 2007; Vecchione et al. 2014) or less positive motivations among women (Hakan and Münire 2014). Within STEM, Lavigne and Vallerand (2010) reported no gender differences in the situational- or contextual-level motivations of high school students in science. In a study of first-year engineering students, Heylen et al. (2012) show more women than men in "good" and "high-quality" motivational orientations. These mixed results highlight the need for further exploration of gender and motivation.

\section{Motivation, gender, and pedagogy in STEM}

The STEM educational community's knowledge of the connections among motivation, gender, and pedagogy is severely underdeveloped. Most of the work linking motivation and gender lies outside of STEM, and most studies that examine gendered expression of intrinsic versus extrinsic motivations are conducted at the contextual level (e.g., why students attend school or participate in a degree program), not at the situational or course activity level. While contextual motivations provide insights into why students enroll and persist in college programs, they do not provide detailed insights necessary for course-level design decisions. Furthermore, since few studies have directly linked women and men's situational motivations to STEM pedagogies, we have little information on how instructors may more effectively select instructional modes and create experiences that engage all students in STEM learning. This study begins to address these research gaps, by characterizing college students' controlled versus autonomous motivations in STEM learning activities, and exploring the connections among gender, pedagogy, and situational motivations in STEM learning environments.

\section{Methods}

Part of a larger mixed-methods investigation aimed at understanding student motivations in the classroom, this paper presents quantitative clustering analyses of situational motivations in undergraduate STEM courses, with a focus on gendered patterns of motivation in different pedagogical environments, as well as the stability or instability of individual students' motivations.

\section{Study participants}

Participants in the study are undergraduate students enrolled in 72 introductory-level STEM courses across 11 higher education institutions. Based on definitions provided by the Carnegie Classification of Institutions of Higher Education (Carnegie Classification n.d.), the institutions in the study were 3 large public doctoral universities, 2 small private baccalaureate colleges, 2 medium private doctoral universities, 1 very small private special focus four-year college, 1 small private special focus 4-year college, 1 medium private baccalaureate college, and 1 large private master's university. Of the 72 courses, 38 (52.8\%) were science, 27 (37.5\%) engineering, 5 (6.9\%) interdisciplinary, and $2(2.8 \%)$ mathematics. One of the interdisciplinary courses integrated engineering, science, and mathematics and the other four courses integrated STEM with liberal arts. Survey respondents included 401 men (45.1\%), 480 women (53.9\%), and 9 students $(1.0 \%)$ of unspecified or non-binary gender.

\section{Measures}

Data were collected via web-based deployment of the Situational Motivation Scale (SIMS) from Guay et al. (2000), which is a 16-item Likert-scaled $(1=$ corresponds not at all; 7 = corresponds exactly) self-report instrument that maps state, or situational, motivation to Deci and Ryan's self-determination continuum (2000). The SIMS measures four types of motivation along the self-determination continuum: amotivation, external regulation, identified regulation, and intrinsic motivation. Each type of motivation corresponds to four SIMS items. Guay et al. (2000) developed and validated the SIMS instrument using five separate studies, which were based on college course activities or college sports activities or a controlled experimental task. Guay et al. (2000) reported adequate internal reliability of each subscale, with Cronbach's $\alpha$ values in the .75 to .93 range. Through exploratory and confirmatory factor analyses, Guay et al. (2000) showed that the four-factor structure of the SIMS measures the SDT constructs of intrinsic motivation, identified regulation, external regulation, and amotivation. Construct validity of the SIMS was supported using motivational determinants and outcomes based on SDT predictions, as well as correlations among subscale variables based on the self-determination continuum (Guay et al. 2000). Guay et al. (2000) also showed that motivations are dynamic and responsive to specific situations and that the SIMS instrument is sufficiently sensitive to measure week-to-week motivational shifts.

The SIMS questionnaire typically begins with the question, "Why are you currently engaged in this activity?" Prior to this prompt, participants in this study were asked to describe their current course activities via open-ended text response to the prompt, "Provide a 
brief description of your current activities in the course, e.g., project work, laboratory experiments, research, lectures, problem sets, etc." In most cases, data were collected weekly over one academic term using the same open-ended course activity prompt. In some cases, the data collection period was shorter, e.g., a multi-week course module. In a few cases, survey responses were collected once in response to a specific course activity described by the instructor. The survey instrument required less than 5 min to complete on average.

Our dataset includes over 5000 unique SIMS responses. Men provided a total of 2064 responses (41.1\%), and women provided 2910 responses (58.0\%), and students of unspecified or non-binary gender provided a total of $43(0.9 \%)$ SIMS responses. Responses from students with unspecified and non-binary gender were included in the overall analysis and pedagogical group comparisons, but not the gender-based analyses. The dataset comprises 2273 (45.3\%) responses from first-year students, 1751 (34.9\%) responses from sophomores, 699 (13.9\%) responses from juniors, and 294 (5.9\%) from seniors. This breakdown of student responses by year reflects the introductory-level course focus of this study, and the response frequencies closely match the overall participant distribution.

Based on text analysis of student weekly activity reports, the research team classified the dominant pedagogy of each course as lecture-based learning or active learning (e.g., project-based, problem-based, and discussion-based). For courses classified as lecture-based learning, greater than $75 \%$ of student responses described course activities as "lecture." For courses classified as active learning, greater than $75 \%$ of student responses described the course activities as "project" or "discussion." In many lecture-based pedagogy courses, "lecture" was used to describe course activities in greater than $90 \%$ of responses. A few courses did not fit within these criteria, and in these cases, classification was determined by the relative amount of "lecture," "project," and "discussion" descriptors. For example, a course with "project" as a descriptor in $44 \%$ of responses and "lecture" in $0 \%$ of responses was classified as active pedagogy. As part of our broader work, we collected data in courses that were not heavily weighted as active or lecture-based pedagogy; however, that data was not included in the present analyses. The active and lecturebased learning classifications represent the primary mode of instruction in courses over the entire academic term, and they are not intended to represent every pedagogical approach or type of activity reported by students in a given class. For example, a course classified as predominantly lecture-based learning may have included active assignments in certain weeks, and courses that made extensive use of project work or discussions may have also incorporated instructor lectures in some weeks. The motivation dataset is weighted toward lecture-based pedagogies, with 3894 responses (76.3\%) from lecture-based learning courses and 1211 responses (23.7\%) from active learning courses.

\section{Data analysis}

The SIMS instrument was assessed using several techniques. Construct validity was tested by comparing the pattern of correlations among SIMS subscales, which are expected to form an ordered pattern based on motivational type adjacencies along SDT's self-determination continuum (Deci and Ryan 2000; Guay et al. 2000). Cronbach's $\alpha$ values were computed to determine internal consistency of the four SIMS subscales. The four-factor structure of the SIMS was verified by confirmatory factor analysis, with comparative fit index (CFI), root mean square error of approximation (RMSEA), and standardized root mean square residual (SRMR) selected as model fit indices.

To analyze students' situational motivations, this study applied quantitative clustering, a technique that has proven useful in characterizing motivations (Braten and Olaussen 2005; Csizer and Dornyei 2005; Ratelle et al. 2007), as it enables examination of the motivational response 'shape' and reveals how individuals simultaneously express a combination of different motivation types. The motivation dataset was explored using several clustering techniques, including agglomerative hierarchical clustering procedures based on between-groups linkage and Ward's method sorting strategies, as well as non-hierarchical iterative partitioning procedures, appropriate for use with continuous data (Aldenderfer and Blashfield 1984). Hierarchical clustering methods applied to the present dataset yielded highly inconsistent cluster sizes and distributions as a function of data sorting order and poor replication, while k-means methods produced more stable and consistent output. Upon assessment of the preliminary cluster analysis output and consideration of meaningful cluster profiles in light of self-determination theory for motivation, the final analysis made use of a kmeans clustering method. As with any clustering technique, basic k-means analysis has certain benefits and drawbacks, depending on the specific application. Drawbacks of kmeans clustering include a dependence on seed values or initial data partition, bias toward similarly sized and shaped clusters, sensitivity to the case order, and reliance on a user-defined number of clusters (Aldenderfer and Blashfield 1984; Everitt et al. 2011). At the same time, k-means clustering is appropriate for use with continuous data or ordinal data that may be treated as continuous as with the calculated SIMS subscale variables, and k-means works directly on raw data and thus is capable of handling large datasets (Aldenderfer and Blashfield 1984; Everitt et al. 2011). 
In addition, many of the drawbacks of k-means, such as the sensitivity to case order and dependence on seed values, may be directly addressed methodologically; and k-means clustering procedures have been previously applied to motivation data with good results (e.g., Dillon and Stolk 2012; Hayenga and Corpus 2010).

Using the entire set of SIMS motivation data, we explored a range of $k$ values from 2 to 15 clusters. By statistically examining differences in the motivation mean values across clusters, and by considering qualitative interpretations of the cluster profiles, we identified a final solution of $k=7$ unique motivation clusters with good conceptual meaning and descriptive utility. The stability and validity of the seven cluster final solution was tested in two ways. First, the initial cluster centroids were defined in several ways, including output from Ward's method hierarchical clustering, cluster centroids from other SIMS datasets, and unspecified values; none of these approaches significantly affected the output. Second, the seven cluster solution was tested through repeated analysis of sorted and split datasets. The same kmeans procedure was applied to the SIMS dataset after sorting randomly and after sorting by different variables such as gender, year of study, student ID, and pedagogy. In addition, replicability of the solution was examined by applying the same k-means technique to randomly selected subsets of the data. Random sorting and splitting of the dataset revealed two stable seven cluster solutions that appeared with equal probability, and with cluster profiles of approximately equal tightness based on mean distances of subscale variables from the cluster centroids. Of the two seven cluster solutions, one was favorable because it separated the low-SDI motivation responses into two distinct clusters with low and high amotivation-a distinction that holds both theoretical meaning and practical value. As such, this cluster was selected as the final solution. In subsequent analyses, each SIMS motivation response was assigned to the nearest cluster centroid. Each cluster is described in terms of mean values from the four motivation subscales of the SIMS instrument.

Following the procedure commonly used in selfdetermination research (Guay et al. 2003; Vallerand 2001), the self-determination index (SDI) for each cluster was calculated as: $\mathrm{SDI}=2 \times($ intrinsic motivation $)+$ $1 \times$ (identified regulation) $-1 \times$ (external regulation) $2 \times$ (amotivation). The SDI, applied in a wide range of motivation investigations (e.g., Blanchard et al. 2007; Guay et al. 2003; Vallerand 2001; Vallerand and Bissonnette 1992), weights subscale constructs according to their position on the self-determination continuum to give a single number that represents students' overall levels of autonomous versus controlled types of motivation. The range of possible SDI scores is -18 to +18 , with higher scores indicating greater self-determination in learning activities.

Cluster distributions for students' motivational responses were compared across lecture-based and active pedagogies and across self-reported gender identities. The Mann-Whitney $U$ test was used to determine if cluster distributions for lecture-based and active pedagogies were significantly different between genders. The stability of students' cluster-assigned motivation profiles, or motivational dynamics, were analyzed in two ways. First, for individuals with at least five SIMS responses (49.3\% of participants), we examined the percentages of students who reported $n$ different motivation response profiles (clusters). Second, as an indicator of the maximum variation in students' motivation response profiles, we analyzed the span of clusters for students who responded to at least five surveys.

\section{Results and discussion}

\section{SIMS instrument validation}

Table 2 shows descriptive statistics, Cronbach's $\alpha$ values, and bivariate correlations for the SIMS subscale variables. The SIMS subscales showed good internal consistency, with Cronbach's $\alpha$ values of intrinsic motivation $=.93$, identified regulation $=.85$, external regulation $=.89$, and amotivation $=.90$. Correlational analysis of the four subscale measures revealed an ordered simplex-like pattern as described by Guay et al. (2000), in which the types of motivation show stronger or weaker, and positive or negative, correlations based on their position along the self-determination continuum. For example, external regulation and amotivation, which are controlled forms of motivation adjacent on the selfdetermination continuum, are positively correlated $(r=$ .36). Intrinsic motivation is positively correlated to identified regulation $(r=.58)$ and negatively correlated with controlled motivations of external regulation $(r=-.31)$ and amotivation $(r=-.33)$. Table 3 presents the survey items and factor loadings for the SIMS instrument. Results of the confirmatory factor analysis indicated that the four-factor structure of the SIMS instrument provided an acceptable fit to the data, with $\chi^{2}(98, N=$

Table 2 Descriptive statistics, reliability, and bivariate correlations for subscale measures of the Situational Motivation Scale (SIMS) questionnaire. $N=5002$

\begin{tabular}{llllllll}
\hline SIMS subscale & $\mathbf{M}$ & SD & $\boldsymbol{a}$ & IM & IR & ER & AM \\
\hline Intrinsic motivation (IM) & 3.84 & 1.48 & .93 & - & $.58^{* *}$ & $-.31^{* *}$ & $-.33^{* *}$ \\
Identified regulation (IR) & 4.90 & 1.22 & .85 & - & $-.10^{* *}$ & $-.44^{* *}$ \\
External regulation (ER) & 4.35 & 1.52 & .89 & & - & $.36^{* *}$ \\
Amotivation (AM) & 2.16 & 1.20 & .90 & & & - \\
\hline
\end{tabular}


Table 3 Results from confirmatory factor analysis of the Situational Motivation Scale (SIMS) questionnaire

\begin{tabular}{lll}
\hline SIMS item & Factor loading & $\mathbf{2}$ \\
\cline { 2 - 3 } Factor 1: Intrinsic motivation (IM) & $\mathbf{1}$ & $\mathbf{3}$ \\
1. Because I think that this activity is interesting. & .85 \\
5. Because I think that this activity is pleasant. & .92 \\
9. Because this activity is fun. & .91 \\
13. Because I feel good when doing this activity. & .86
\end{tabular}

\section{Factor 2: Identified regulation (IR)}

2. Because I am doing it for my own good.

6. Because I think that this activity is good for me.

10. By personal decision.

14. Because I believe that this activity is important for me.

Factor 3: External regulation (ER)

3. Because I am supposed to do it.

7. Because it is something that I have to do.

11. Because I don't have any choice.

15. Because I feel that I have to do it.

\section{Factor 4: Amotivation (AM)}

4. There may be good reasons to do this activity, but personally I don't see any.

8. I do this activity but I am not sure if it is worth it.

$5002)=3206.46, \mathrm{CFI}=0.95, \mathrm{SRMR}=0.07, \mathrm{RMSEA}=$ $0.08, p<.001$.

\section{Cluster analysis and complex motivational responses}

The final solution to clustering analysis of the situational motivation data shows seven motivational response profiles, ranging from a highly control-oriented to a highly autonomous response. These seven motivational response profiles, or unique clusters, are illustrated in Fig. 1. The seven clusters are named Autonomous (AU), High Autonomous-High External (AU-EX), High IdentifiedHigh External (ID-EX), Moderate Identified (M-ID), Neutral $(\mathrm{N})$, External (EX), and High Amotivation (AM). Table 4 provides descriptive statistics for each cluster centroid in terms of SIMS motivation subscales, as well as the calculated self-determination index (SDI) for each cluster. The final solution reflects a wide spectrum of motivational responses, with SDI values ranging from -10.5 to +10.4 on the -18 to +18 scale, and with low to high values on all four subscale variables. Two clusters (M-ID and ID-EX) share a similar SDI value but represent significantly different motivational attributes. The seven cluster solution explained $71.0 \%$ of the variance in intrinsic motivation, $58.3 \%$ of the variance in identified regulation, $68.2 \%$ of the variance in external regulation, $66.1 \%$ of the variance in amotivation, and $82.0 \%$ of the variance in the calculated SDI value, which weights and combines the four motivation subscale measures.

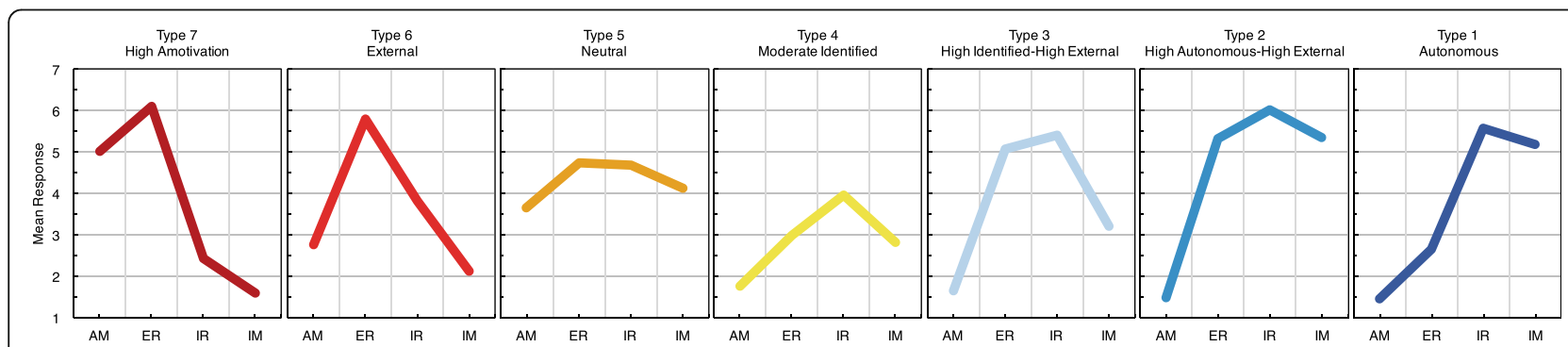

Fig. 1 Motivational response profiles identified in this study, ordered from lowest SDI (cluster AM, left) to highest SDI (cluster AU, right). AM amotivation, ER external regulation, IR identified regulation, IM intrinsic motivation 
Table 4 Comparison of motivational response profiles (cluster centroids) based on SIMS subscale means and SDI values

\begin{tabular}{|c|c|c|c|c|c|c|c|c|c|c|c|c|c|c|}
\hline \multirow[t]{3}{*}{ SIMS subscale } & \multicolumn{14}{|c|}{ Cluster response profile } \\
\hline & \multicolumn{2}{|l|}{$\begin{array}{l}\text { Type } 7 \\
\text { AM }\end{array}$} & \multicolumn{2}{|c|}{$\begin{array}{l}\text { Type } 6 \\
\text { EX }\end{array}$} & \multicolumn{2}{|c|}{$\begin{array}{l}\text { Type } 5 \\
\text { N }\end{array}$} & \multicolumn{2}{|c|}{$\begin{array}{l}\text { Type } 4 \\
\text { M-ID }\end{array}$} & \multicolumn{2}{|c|}{$\begin{array}{l}\text { Type } 3 \\
\text { ID-EX }\end{array}$} & \multicolumn{2}{|c|}{$\begin{array}{l}\text { Type } 2 \\
\text { AU-EX }\end{array}$} & \multicolumn{2}{|c|}{$\begin{array}{l}\text { Type } 1 \\
\text { AU }\end{array}$} \\
\hline & $\bar{M}$ & $S D$ & $\bar{M}$ & $S D$ & $\bar{M}$ & $S D$ & $\bar{M}$ & $S D$ & $\bar{M}$ & $S D$ & $\bar{M}$ & $S D$ & $\bar{M}$ & $S D$ \\
\hline Intrinsic motivation & 1.60 & 0.61 & 2.12 & 0.72 & 4.13 & 0.78 & 2.82 & 0.86 & 3.20 & 0.80 & 5.36 & 0.77 & 5.19 & 0.85 \\
\hline Identified regulation & 2.44 & 1.09 & 3.82 & 0.88 & 4.69 & 0.73 & 3.97 & 0.89 & 5.41 & 0.71 & 6.03 & 0.68 & 5.57 & 0.75 \\
\hline External regulation & 6.10 & 0.92 & 5.81 & 0.84 & 4.75 & 0.81 & 2.98 & 0.89 & 5.07 & 0.85 & 5.33 & 0.92 & 2.66 & 0.82 \\
\hline Amotivation & 5.01 & 0.93 & 2.76 & 0.87 & 3.66 & 0.81 & 1.76 & 0.77 & 1.66 & 0.57 & 1.49 & 0.62 & 1.44 & 0.56 \\
\hline Self-Determination Index (SDI) & -10.47 & 3.08 & -3.28 & 2.35 & 0.88 & 2.61 & 3.11 & 2.88 & 3.42 & 2.17 & 8.44 & 2.40 & 10.41 & 2.60 \\
\hline
\end{tabular}

The AU cluster represents the most positive situational motivation response profile, characterized by high identified regulation (IR) and intrinsic motivation (IM) levels, and low external regulation (ER) and amotivation (AM) levels. This highly self-determined response reflects engagement in learning for reasons of interest, enjoyment, and inherent satisfaction as well as a sense of value, importance, and utility. The AU cluster is similar to motivation responses labeled in previous studies as "good quality" (Vansteenkiste et al. 2009), "self-determined" (Boiché et al. 2008; Boiché and Stephan 2014), "autonomous" (Gillet et al. 2017), or "truly autonomous" (Ratelle et al. 2007).

The AU-EX cluster shows high levels in all types of motivation except amotivation-a motivational profile previously described as "high autonomous-controlled (AU-C)" (Ratelle et al. 2007), "high quantity motivation" (Vansteenkiste et al. 2009), "strongly motivated" (Gillet et al. 2017), or "additive" (Boiché and Stephan 2014). While not truly autonomous, AU-EX reflects a high level of self-determination and indicates that a student is interested in the course activity but also sensitive to external rewards or pressure.

The ID-EX cluster is characterized by high levels of identified regulation and external regulation, with moderately low-intrinsic motivation and low amotivation. With a SDI value of 3.42, the ID-EX response is moderately self-determined, but students' positive engagement arises from a sense of value rather than a sense of enjoyment or interest. Students with the ID-EX response likely perceive usefulness or importance in their course activities, but they couple this perceived value more strongly with extrinsic pressure or obligation (external regulation) than internalized interest and enjoyment (intrinsic motivation). In addition, the low amotivation value indicates that students effectively perceive connections between their actions and outcomes and are able to identify motives for engagement in the course activities. Ratelle et al. (2007) referred to this type of motivation as "moderate autonomous-controlled (AU-C)" and found this to be a common profile of contextual-level motivation among high school students. While not highly self-determined, Ratelle et al. (2007) associated the moderate AU-C with certain desirable high school student outcomes such as "high persistence and achievement, low absenteeism, and high cognitive and affective functioning." De Bilde et al. (2011) suggest that futureoriented students may express high levels of identified regulation without necessarily deriving a sense of inherent pleasure or satisfaction in the activity that may give rise to intrinsic motivation. According to de Bilde et al. (2011), students who focus on longer-term consequences of their engagement, as opposed to near-term enjoyment, may shift their motivational attitudes toward instrumental goals, which may help to explain the coupling of identified regulation with high external regulation in the ID-EX response.

The M-ID cluster response profile has a positive balance of autonomous versus controlled motivations and a positive SDI value of 3.11 , but it reflects overall lower motivational intensity. This motivation response with low intensity and relatively flat response shares certain similarities with what other authors call "moderately unmotivated" (Gillet et al. 2017) or "low autonomous-low controlled" (Ratelle et al. 2007), particularly the low to moderate levels of IM and ER. These previously reported response profiles, however, also exhibit moderately high levels of amotivation, whereas the M-ID cluster shows distinctly low amotivation. This cluster may indicate a student who is positively but more passively engaged in the class activities or a student who does not feel pressured or excited to engage but anticipates only moderate value from a given activity. In the context of college courses, this low intensity yet moderately selfdetermined motivational response is important to understand, as it may represent a positive inclination to engage that is linked to uncertain needs satisfaction. The right classroom conditions or learning activity designs may serve to boost the overall signal, bringing the M-ID response closer to the AU-EX or AU responses.

The $\mathrm{N}$ cluster response combines moderate levels of both autonomous and controlled motivations. In their study of contextual motivation profiles, Ratelle et al. (2007) found a similar pattern, named "low autonomouslow controlled (Low AU-C)," expressed by about $25 \%$ of 
first-year college students, and more commonly reported by men compared to women. Ratelle et al. (2007) associated the Low AU-C response with low persistence and achievement, and high dropout, indicating that this type of motivation may be of concern in the college classroom; however, the Low AU-C profile showed higher amotivation and lower external regulation than the $\mathrm{N}$ cluster in the present study. A closer match to the $\mathrm{N}$ cluster response is the "moderate" motivation profile described by Boiché et al. (2008), which was associated with students' high levels of effort but poor performance.

The EX cluster response is dominated by a high ER signal, which is expressed alongside moderate IR, moderately low AM, and low IM. The EX cluster is a situational motivation response not previously reported in the literautre. Previous clustering analyses of motivation data include highly controlled responses, but these are typically linked to high, or even dominant, amotivation signals. As examples, the "controlled" responses reported by Ratelle et al. (2007) and Gillet et al. (2017), the "non self-determined" response by Boiché et al. (2008), and the "low self-determined/high controlled" reported by Liu et al. (2009) show high amotivation values, often substantially higher than the external regulation values. The closest match to the EX cluster profile may be the "poor quality motivation" cluster reported by Vansteenkiste et al. (2009), which shows high controlled motivations based on combining the external regulation and introjected regulation signals, along with low autonomous motivations based on combining identified regulation and intrinsic motivation values. It is unclear if amotivation is included in the Vansteenkiste et al. (2009) "poor quality motivation" cluster profile. Given the wording of the SIMS subscale items, which emphasize negative forms of pressures rather than rewards, students who show the EX response feel strongly that they have no choice but to engage in a learning activity, or feel they "are supposed to" or "have to" engage. The moderate IR value for this cluster suggests that students may find some value or importance, but their motivations are largely based on externalized pressuring contingencies.

The AM cluster response is described by extremely high levels of external regulation, high amotivation, and low identified regulation and intrinsic motivation. The AM response is similar to the "controlled" profiles in Gillet et al. (2017) and Ratelle et al. (2007), and the "non self-determined" responses in Boiché et al. (2008) and Boiché and Stephan (2014); however, each of the previously reported clusters show amotivation as the strongest signal, while amotivation is lower than external regulation in the AM cluster. As the most controlled and least self-determined situational motivation response, we expect AM to appear when students experience high levels of stress and extrinsic pressure, feelings of uncertainty about what they are doing, and no sense of enjoyment, interest, or value in the learning.

\section{Motivation in STEM courses}

Cluster distributions for the complete dataset are shown in Fig. 2. Analysis of the overall distribution reveals several insights. First, the overall responses are more heavily distributed toward clusters with positive SDI values, with $69 \%$ of all responses falling into the M-ID, ID-EX, AU-EX, and AU classifications. It is clear that the college-level STEM courses included in this study are generally successful in prompting positive situational motivational responses among most students in most learning activities. Second, at $22.8 \%$ of responses, the AU cluster represents the most commonly reported form of motivation-another positive indicator for the ways college STEM courses may encourage positive forms of engagement. Third, at $4.3 \%$ of responses, the highly controlled AM form of motivation is relatively uncommon. The infrequent expression of highly controlled motivations may be another general indicator of success in STEM courses, or it may be an anticipated result at the college level. In their study of contextual-level motivations of high school and college students, Ratelle et al. (2007) reported that the controlled motivational profile was sparsely populated (less than $8 \%$ of responses) in high school settings, and the controlled profile did not emerge in their clustering analysis of college students' motivations. In contrast to the Ratelle et al. (2007) findings, a study of secondary students in project-based learning by Liu et al. (2009) showed over $28 \%$ of students in a "low self-determined/high controlled" group. In a study of first-year college students in science courses, Boiché and Stephan (2014) showed 9\% of students in a "non-self-determined" group with high ER and AM scores.

\section{Motivation and pedagogy}

Cluster distributions for lecture-based and active pedagogies are shown in Fig. 2. Analyses of the motivational response profiles by pedagogy using the Mann-Whitney $U$ test showed a significant difference in the cluster distribution for active $(N=1213)$ and lecture-based $(N=3789)$ learning $(U=3077924, p<.001)$, with more positive situational motivations in active learning environments compared to lecture-based learning environments. The ID-EX cluster, with strong IR and moderate ER and IM, was the most common motivational response in lecture-based pedagogies, although the distribution of responses in lecture-based settings is relatively even across all motivational profiles except AM. In contrast, the AU cluster is the most common motivational response in active learning courses, with over $44 \%$ of responses classified as this highly self-determined form of engagement. Interestingly, the ID-EX response represents $20.6 \%$ of responses in 

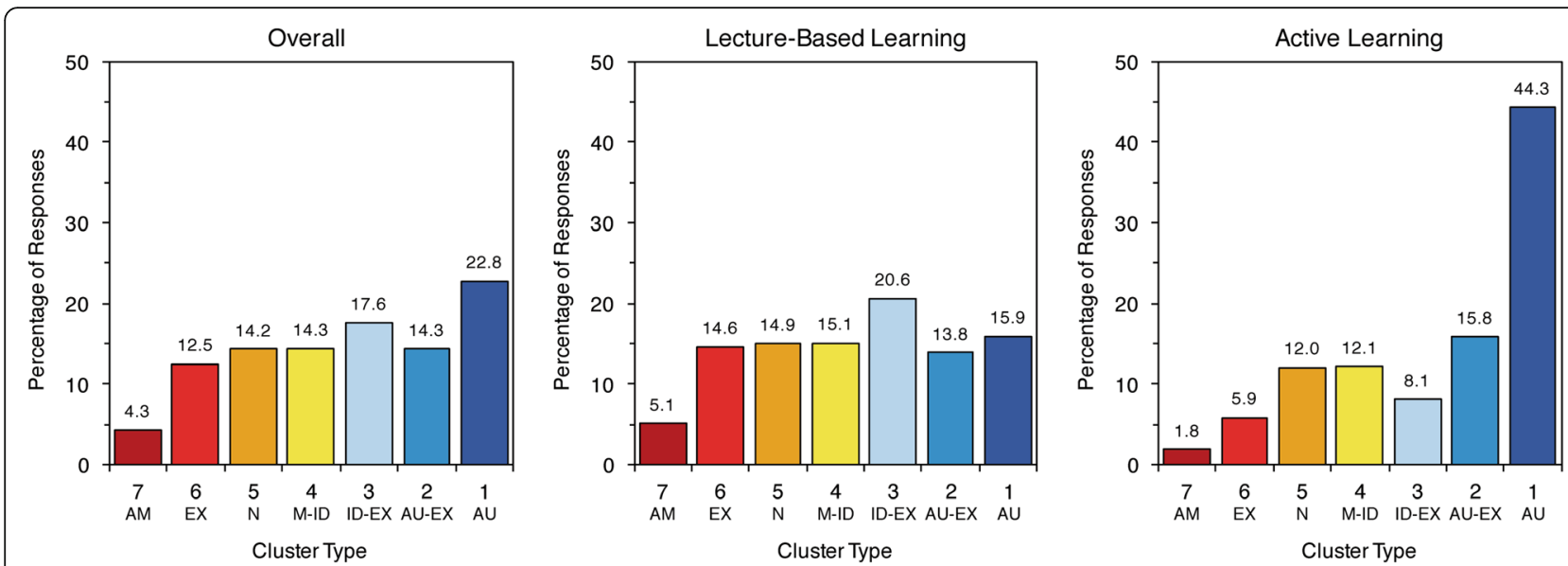

Fig. 2 Overall distribution of motivational responses in STEM college courses (left), and differences in cluster distributions for lecture-based (middle) and active pedagogies (right). Clusters are arranged from lowest SDI (left) to highest SDI (right)

lecture-based settings, and only $8.1 \%$ of responses in active learning settings. In addition, the controlled motivation EX cluster represented $14.6 \%$ of student responses in lecture-based pedagogies, and only $5.9 \%$ of responses in active pedagogies.

Figure 2 illustrates a sharp contrast between students' situational motivations in lecture-based versus active course activities. Yet, these findings align well with research that shows more positive situational motivations in constructivist compared to didactic teaching environments (Nie and Lau 2010) and studies that illustrate that students express internalized motivations in courses with active pedagogies (Dillon et al. 2016; Herman et al. 2017; Stolk and Martello 2015). Examining the frequency of students' ID-EX and AU responses across pedagogies suggests that feelings of interest and enjoyment may play a key role in promoting positive motivations in active learning environments. The frequent ID-EX response in lecture-based settings is described by the co-occurrence of internalized importance and externalized pressure. The ID-EX response has a positive SDI, but in this case, self-determined drive arises more from a sense of importance (identified regulation) than a sense of enjoyment or interest (intrinsic motivation). In lecture-based courses, learners appear to frequently disconnect feelings of importance from feelings of joy, perhaps finding these experiences less interesting but nonetheless valuable. Motivations in the active learning classes, on the other hand, are dominated by two motivational profiles (AU$\mathrm{EX}$ and $\mathrm{AU}$ ) that show high-intrinsic motivation values as well as co-occurrence of identified regulation. These findings suggest that active learning is more effective than lecture-based learning in enabling students to connect their personal interests and passions with a strong sense of meaning, importance, and relevance. While lecture-based activities foster internalized motivations in the form of perceived value and importance, promoting a deeply internalized sense of interest, excitement, and enjoyment not tied to contingent rewards and punishments may be fundamentally more challenging in lecture-based settings. The challenge of intrinsic motivation in lecture-based settings may relate to learners' basic psychological need for autonomy. Prior studies suggest that autonomy is essential to intrinsic motivation (Deci and Ryan 2000), but learners may struggle to feel a sense of volition, control, and personal choice in classrooms where instructors exert more control. Given intrinsic motivation's importance to learner engagement, self-regulation, performance, persistence, and psychological well-being (e.g., Deci and Ryan 2000; Ratelle et al. 2007; Vansteenkiste et al. 2009), future work should examine the underlying psychological reasons for the observed motivational differences across STEM pedagogical settings, as well as specific learning environmental conditions that give rise to situational responses with high levels of intrinsic motivation.

\section{Motivation, pedagogy, and gender}

Identifying how students with different gender identities express motivations in different courses was a key goal of this study. Using pedagogical classifications and selfreported gender identity as an independent variable in our clustering analyses, we examined how distributions of motivation responses vary with gender and explored if gendered differences in motivational profiles are influenced by the instructor's pedagogical approach. When considering men and women gender identities separately, the motivation cluster distributions vary significantly across pedagogical classifications, with both men and women expressing more positive forms of motivation in active learning. Mann-Whitney $U$ tests showed significant differences in motivations for men in 
primarily lecture $(N=1483)$ versus active $(N=573)$ learning settings $(U=331097, p<.001)$, as well as for women in lecture $(N=2297)$ versus active $(N=606)$ learning settings $(U=379893, p<.001)$. Mann-Whitney $U$ tests also showed that the motivation cluster distributions within both lecture-based and active learning settings are significantly different by gender. Indeed, strong gendered patterns in student motivations are apparent when women and men's responses are compared across pedagogies.

As shown in Fig. 3, the strongest gender-based differences in motivation appeared in lecture-based learning environments, with a Mann-Whitney $U$ test indicating significantly different cluster distributions $(U=1888561$, $p<.001)$ for men $(N=1483)$ compared to women $(N=$ 2297). In courses with lecture-based learning activities, women register higher externalized motivations and lower autonomous motivations compared to men. The most frequent motivational response profile for women in lecture-based courses was ID-EX, characterized by the co-occurrence of strong internalized value and extrinsic pressure. The EX response emerged as the second most frequent motivational response for women in lecturebased settings. This gender-specific response is concerning, given that the EX response represents a controlled form of situational motivation, described by high external regulation and low internalization. SDT suggests that controlled motivations arise when basic psychological needs are thwarted (Deci and Ryan 2000), and motivation research shows that controlled motivations are associated with a broad range of undesirable outcomes such as low cognitive engagement, surface-level learning, poor self-regulation, high anxiety, and dropout (e.g., De Bilde et al. 2011; Pelletier et al. 2001; Vansteenkiste et al. 2009). Compared to women, men in lecture-based settings more frequently reported $\mathrm{AU}$ and $\mathrm{N}$ responses, and less frequently showed the low intensity value-based drive of the M-ID cluster.

In courses with active learning, the difference in cluster distributions of women $(N=606)$ and men $(N=$ $573)$ is small but nonetheless significant $(U=154807, p$ $=.001)$. For both women and men, active learning supports highly self-determined motivations, with the AU cluster making up $47.8 \%$ of women's responses and

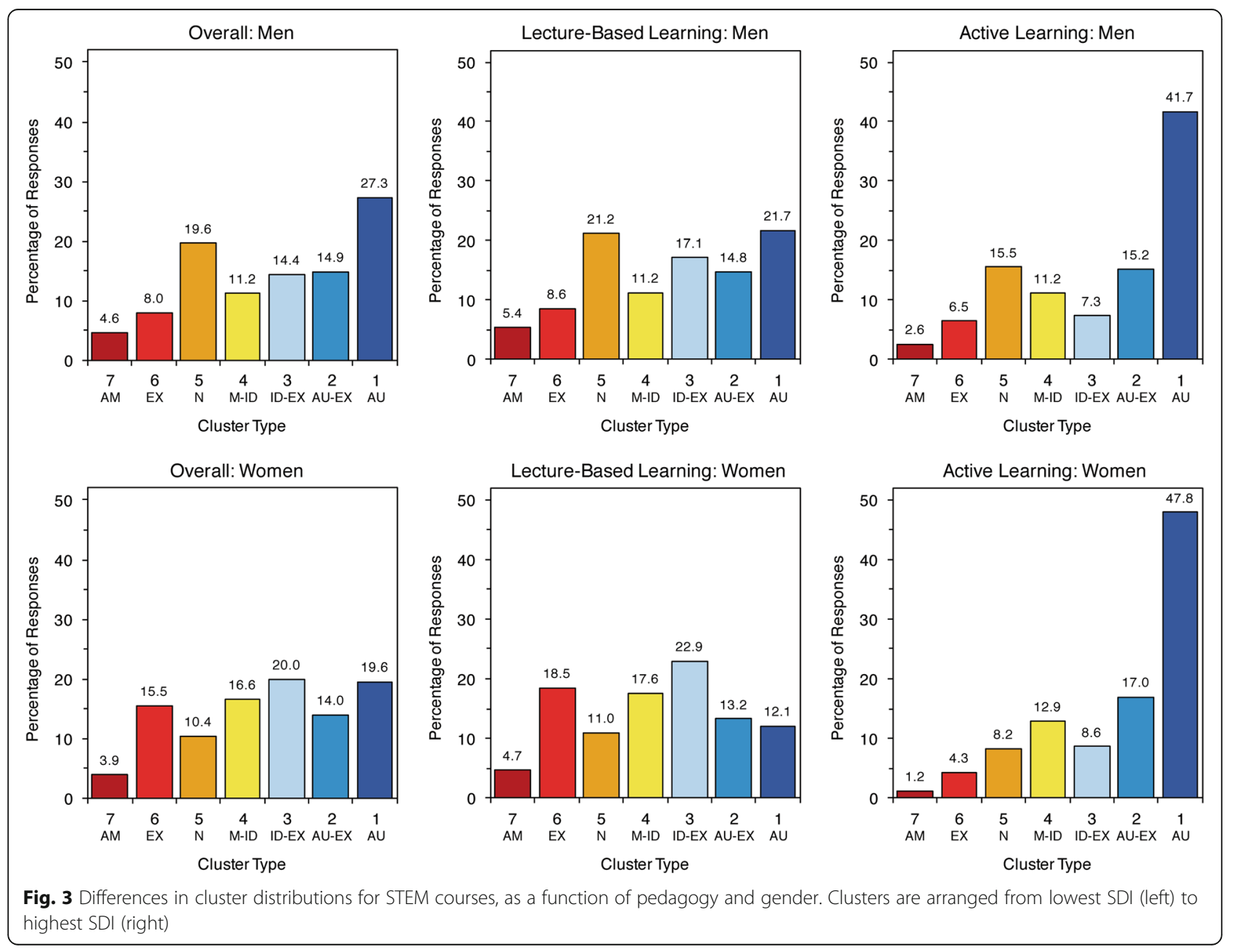


$41.7 \%$ of men's responses. In addition, over $75 \%$ of men's and $86 \%$ of women's responses are classified into clusters with positive SDI values (types 1-4). Active learning approaches appear to provide slight motivational benefits to women compared to men, as women's responses distribute more heavily across the autonomous clusters, while men more often express the neutral (Type 5) motivational response (Fig. 3).

The combination of Figs. 2 and 3 shows a powerful pedagogy-motivation connection: active pedagogies support balanced motivational profiles by gender, as well as more positive motivations for all students compared to lecture-based pedagogies. Analyses of students' qualitative responses will provide the most direct explanations of how women and men in this study experienced their lecture-based versus active course environments. Although our qualitative analyses in this mixed-methods study are ongoing, we can gain insights on the gendered motivational responses from existing literature.

Gender-related differences in self-efficacy and interests are proposed to arise, at least in part, from gender-role stereotypes and gendered socialization processes in traditionally male dominated domains such as mathematics and engineering (Bastalich et al. 2007; Hoffmann 2002; Meece and Painter 2008; Tonso 2006). Development of gender identity can lead to gender-typed interests and perceptions of competence beginning at an early age (Eccles et al. 1993), and these orientations may be actively reinforced or reduced by activities, interactions, cues, norms, and opportunities in an environment such as a classroom (Wigfield and Cambria 2010). Instructional conditions can have direct influence on competence and interest, which can impact both near-term situational and long-term sustained motivations (Greene et al. 2004; Hidi and Renninger 2006; Hoffmann 2002; Krapp 2005). In examining the cluster distributions by gender, it is clear that with lecture-based learning, women students more often experience a stronger sense of externalized control and find fewer opportunities for value-, interest-, and enjoyment-based internalization of the learning activities in these courses. Given that intrinsic motivation shows the largest gap between men and women in lecture-based courses and that intrinsic motivation is strongly influenced by the basic psychological needs satisfaction of autonomy, competence, and relatedness, the results suggest women are not finding as much support in their environment as men in lecture-based courses (Deci and Ryan 2000; Stolk, Zastavker, et al. 2018). We are currently exploring the degree to which each of these basic psychological needs are satisfied in different STEM courses.

\section{Stability analysis}

Our examination of the stability and change of students' motivations was prompted by questions regarding the dynamic versus static nature of students' situational motivations during the academic term, an approach previously reported by Hayenga and Corpus (2010). With weekly surveying used in this study, we were able to reveal variations in students' motivational responses during the semester that would have been obscured with pre-post measurements sometimes used in motivation studies (Fig. 4). Early in the study, we recognized that some students express relatively stable situational motivations and cluster assignments as they progress through introductory STEM courses, while other students show extreme highs and lows in situational motivations during a course, or upward or downward trends in motivation over the academic term. For example, the student response in Fig. 4 shows positive starting and ending points for situational motivations, with multiple downward inflection points where SDI values shift into the negative as a result of higher amotivation and external regulation, and lower identified regulation and intrinsic motivation. Correlational and distributional analyses of the cluster assignments and cluster variation as a function of survey responses helped to shed light on these motivational dynamics.

Our analyses revealed several insights into the stability and variation of student motivation. First, most students express several distinct motivation profiles (clusters) in a given course, illustrating the dynamic nature of situational motivation (Fig. 5, left). For students who completed five or more survey responses, about $86 \%$ of students report at least two unique cluster profiles in a given course, and nearly half of students express at least three cluster profiles. Importantly, we did not find a significant correlation between the number of survey responses and the motivation profile, i.e., students with more positive situational motivations were not more inclined to respond to the weekly surveys, or vice versa. Second, most students show situational motivation transitions during an academic term that span a relatively wide range of cluster profiles (Fig. 5, right). About two thirds of students report motivation clusters that span three or more cluster profiles (e.g., responses span clusters AU to ID-EX, AU-EX to M-ID, ID-EX to N, etc.), while about a third of students report motivation clusters that span one or two cluster profiles.

The intra-course variations in individual responses revealed by this analysis begin to challenge embedded beliefs about the fixed nature of learner motivation as well as research reports that indicate relative stability in motivations, while simultaneously highlighting opportunities for instructors to act as empowered designers of positive motivation-supportive experiences.

\section{Implications for practice}

These findings have important implications for practitioners concerned with providing inclusive and student- 


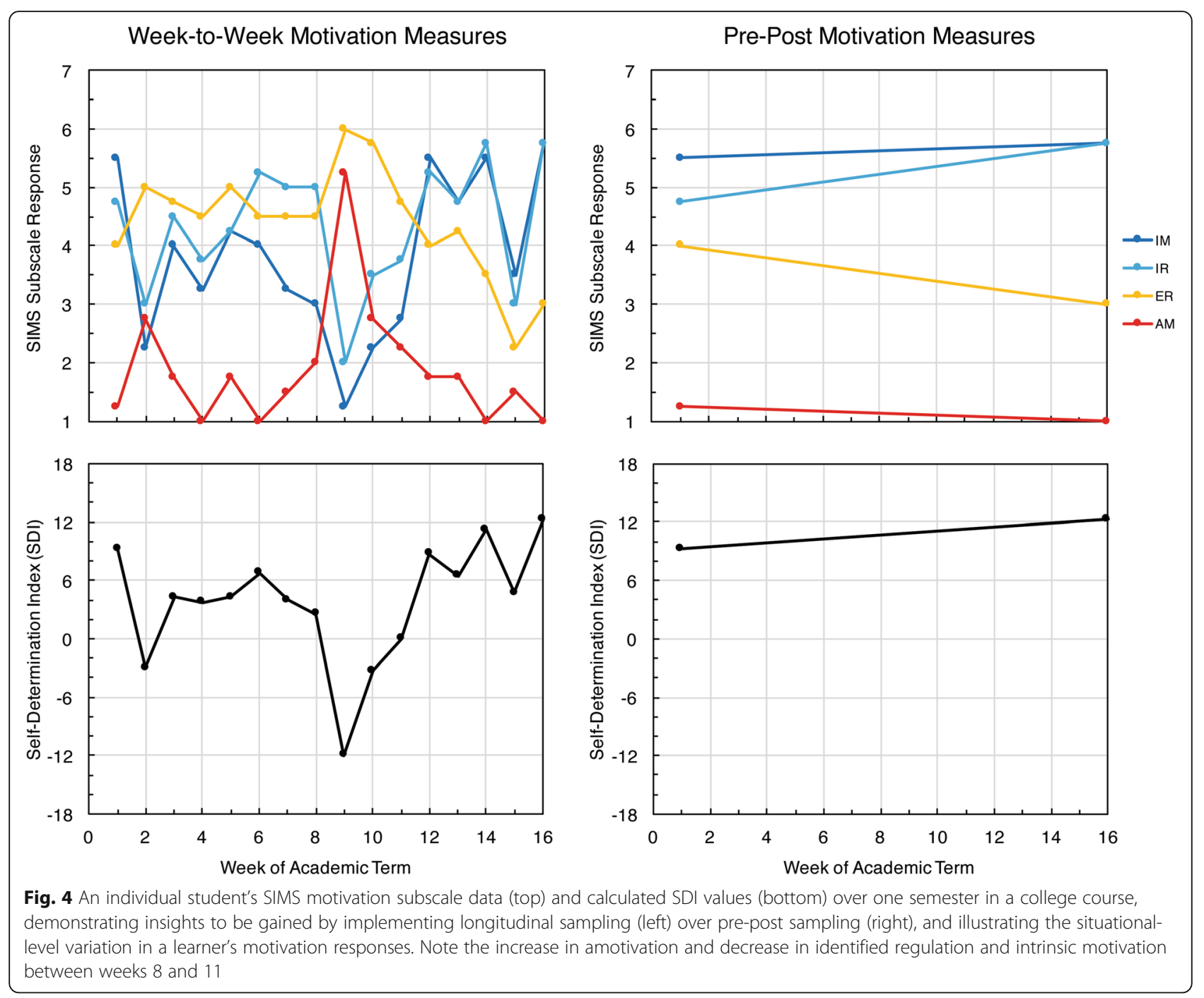

centered learning experiences. The concept of motivational co-expression illustrated with the motivational response profiles emphasizes a need for instructors to move past the simple "intrinsic" or "extrinsic" labels, and toward an appraisal that recognizes how students adopt complex forms of drive in response to classroom activities. The gender-based patterns in students' motivations across different pedagogical environments raise questions about how instructors may use course design to effectively promote the positive motivational engagement of all students through their pedagogical choices. In the same way we may not wish to see women and men leave STEM courses with significantly different skills or understandings, we might not want women and men to engage technical learning with dramatically different motivations or exit technical courses with vastly different levels of perceived value, interest, and enjoyment. Given that the motivations of women and men are both more similar, and more positive overall, in courses that employ active pedagogies, a systemic shift to active, student-centered learning may be key to a more inclusive and engaging STEM learning environment.

Instructors play a critical role in the shift to positive motivations in STEM courses. Recent research shows that instructor beliefs about motivation contribute to their course approaches, goal framings, interactive style, and, ultimately, their students' motivations (Jang 2019; Reeve et al. 2004). Instructors who adopt autonomysupportive motivational beliefs are more likely to create experiences and environments that support autonomy and lead to positive learner engagement (Fong et al. 2019), and more likely to use effective teaching strategies including higher-order learning, reflective learning, integrative learning, and collaborative learning (Stupnisky et al. 2018). As with students, however, the motivational attitudes of faculty are not fixed. Although educators often 

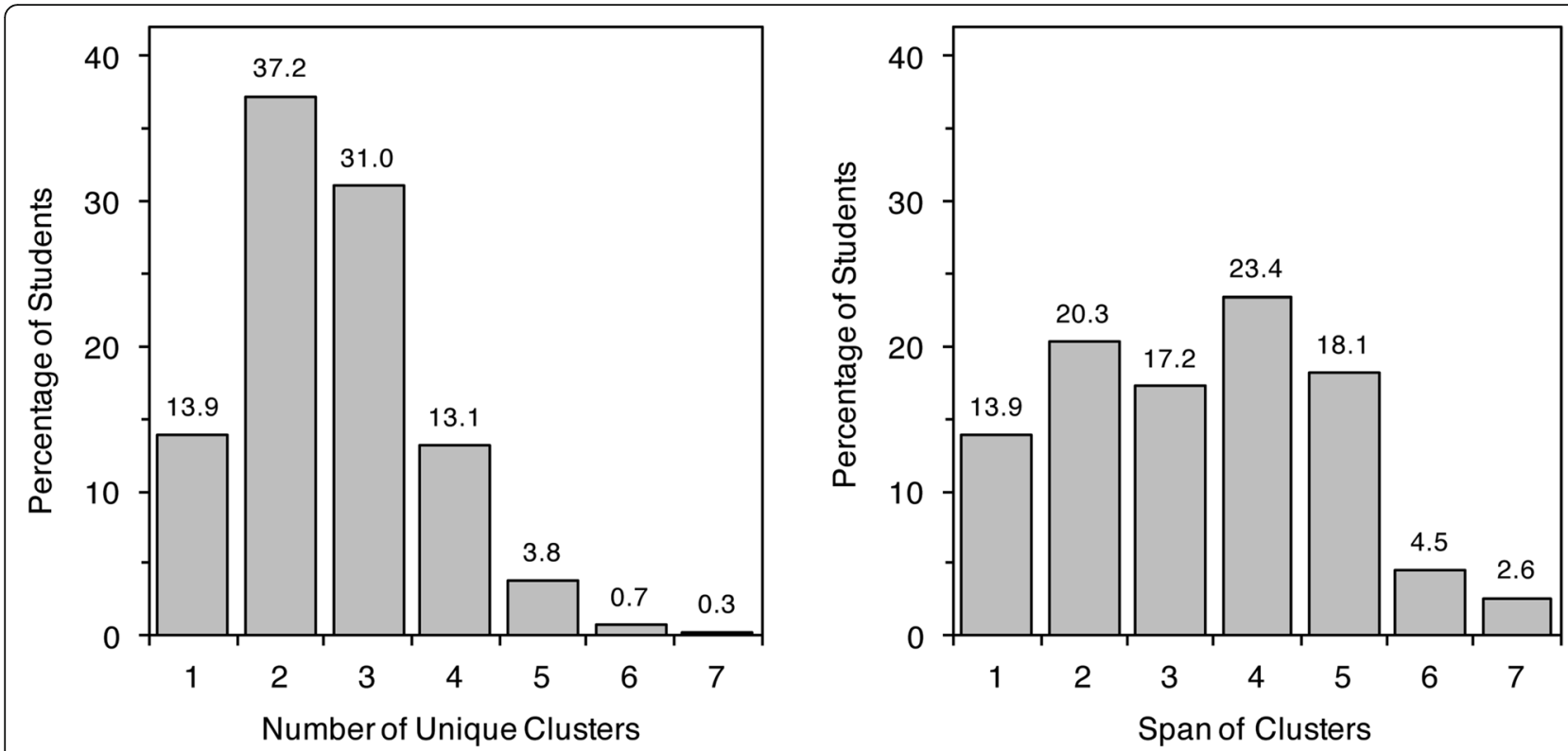

Fig. 5 Situational motivation stability and transition indicators for individuals with at least five responses to the weekly motivation survey. The left graph shows the percentages of students who reported $n$ unique motivation response profiles (clusters). The right graph shows percentages of students who transitioned different distances across the cluster profiles. A span of 1 on the right graph represents individuals with cluster membership that did not change; a span of 3 indicates a shift from Cluster AU to Cluster ID-EX, from cluster EX to Cluster M-ID, etc

feel pressured toward controlling approaches (Reeve 2009), research on autonomy-supportive interventions illustrates that instructors can "upgrade the quality of their motivating style" (Cheon et al. 2018) by adapting their approaches and improving their skills to better address students' basic psychological needs and support autonomous learner drive (Cheon and Reeve 2015). According to Vansteenkiste et al. (2018), "the basic attitude underlying an autonomy-supportive style is one of curiosity, openness, and empathic understanding, which allows teachers to connect with the learners' frame of reference such that learners have the feeling they can be themselves in relation with their teacher." This student centeredness can manifest in many ways, such as enabling student choice and control in assignments, encouraging individual expression, eliciting students' perspectives and validating students' experiences, providing multiple ways to identify relevance, and clearly articulating pedagogical decisions and constraints (Vansteenkiste et al. 2018). From a selfdetermined motivation perspective, the goal for instructors is always the same: bolster learners' sense of competence, relatedness, and autonomy.

Academic administrators also play an important role in fostering positive motivations, by providing developmental opportunities for faculty, as well as an autonomysupportive academic work environment. Educators often feel pressured toward controlling approaches (Reeve 2009); but when they feel self-determined and a sense of psychological need support, they are more likely to foster self-determination among students (Fong et al. 2019; Roth et al. 2007; Stupnisky et al. 2018). Educators must consider motivations throughout their academic systems to realize the full potential of internalized motivations in learning.

\section{Limitations}

The present analysis has several notable limitations. First, this paper presents a characterization of motivation with interpretations based on motivation theory and empirical research, not an explanation of student motivations based on analysis of qualitative student response data or direct observations. Second, while nominally framed as a study of motivations in STEM courses, the dataset is heavily weighted toward science and engineering and lightly weighted toward mathematics and interdisciplinary classes. Further studies of situational motivations in diverse college mathematics and technology courses would elucidate the transferability of findings across disciplinary domains. Third, this analysis presents an aggregate of situational motivations based on gender and pedagogical groupings in STEM courses across a range of institutions. The results presented here do not illustrate differences that may exist between institutions, disciplinary domains, or years of study; nor does the analysis examine motivational variations that exist within particular pedagogical approaches such as lecture-based or project-based learning. Pedagogy was classified at the overall course level and does not reflect differences that may occur in different weeks or particular assignments of the course. The aggregated motivational responses do not reflect the lived experiences of 
individual students in specific settings, nor do they provide commentary or evaluation on specific instructors or courses. In addition, since this study was focused on situational motivations in specific course environments, it did not include aspects of departmental or institutional learning culture that may shape students' contextual-level motivations and provide a "top-down" influence on situational motivations, as described by SDT's hierarchical model for motivation. Finally, this paper treats gender as a binary variable, per the socioculturally constructed classifications traditionally used in social science research. Although students in the study were provided with an opportunity to identify as nonbinary or non-specified gender, the group sizes for these classifications were too small to include in the present analyses. The authors recognize that treating gender as a binary variable potentially presents an unintended consequence of further marginalizing minority student populations through lack of inclusion in the analysis and reporting. Future analyses will seek to examine personcentered narratives of the situational motivations of marginalized and severely underrepresented groups in STEM.

\section{Conclusions}

This analysis illustrates several key findings. First, students' situational motivations in STEM courses are complex and multifaceted: individuals express different levels of internalized and externalized motivations at any given time. Second, situational motivations are more positive in courses that employ active pedagogies, as compared to lecture-based courses. Third, different pedagogical environments prompt different motivational responses by gender. The strongest gender differences appear in lecture-based learning settings, with women reporting lower autonomous motivations and higher controlled motivations compared to men. Motivational response profiles of women and men are both more similar and more positive overall in STEM courses that employ active pedagogies such as project- and discussion-based learning. Fourth, while individuals' situational motivational responses in STEM courses may be stable or dynamic, this study shows that the majority of students report multiple unique motivation clusters that span three or more cluster profiles.

These findings have important implications for practitioners concerned with the design of inclusive and student-centered learning experiences. The concept of motivational co-expression, revealed by the cluster analysis, emphasizes a need for instructors to move past simple "intrinsic" or "extrinsic" labels and toward an appraisal that recognizes how students adopt complex forms of drive in response to classroom activities. The stability analyses challenge embedded beliefs about the fixed nature of learner motivation. The gender-based analyses raise questions about how instructors may more effectively promote the positive motivational engagement of all students through their course design and implementation decisions.

\section{Abbreviations}

STEM: Science, technology, engineering, and mathematics; SDT: Selfdetermination theory; SRL: Self-regulated learning; SIMS: Situational motivation scale; SDI: Self-determination index; IM: Intrinsic motivation; IR: Identified regulation; ER: External regulation; AM: Amotivation; AUC: Autonomous-controlled; AU: Autonomous; AU-EX: High autonomous-high external; ID-EX: High identified-high external; M-ID: Moderate identified; N: Neutral; EX: External

\section{Acknowledgements}

The authors wish to thank the entire motivation research team for their contributions to the data collection, analysis, and visualization, as well as the many faculty partners who engaged in the motivation research study and enabled data collection in their undergraduate STEM courses. The authors extend special thanks to Alex Dillon, for his exploration of quantitative cluster analysis methods and data visualization techniques for this study.

\section{Authors' contributions}

All authors were major contributors to the conception, design of work, interpretation of data, and writing the manuscript. JS and MDG conducted the data acquisition and analysis. The authors read and approved the final manuscript.

\section{Funding}

NSF Disclaimer: Elements of this paper were supported by the National Science Foundation (NSF) grants DUE-1322684, DUE-1445950, EEC-1265117. Any opinions and findings expressed in this material are those of the authors and do not necessarily reflect the views of NSF.

\section{Availability of data and materials}

The anonymized and de-identified datasets used and/or analyzed for the current study are available from the corresponding author upon reasonable request.

\section{Declarations}

Competing interests

The authors declare that they have no competing interests.

\section{Author details}

${ }^{1}$ Olin College of Engineering, 1000 Olin Way, Needham, MA 02492, USA. ${ }^{2}$ Department of Engineering, Wake Forest University, Winston-Salem, NC 27109, USA.

Received: 18 September 2020 Accepted: 4 March 2021

Published online: 12 May 2021

\section{References}

Aldenderfer, M. S., \& Blashfield, R. K. (1984). Cluster analysis. SAGE Publications, Inc. https://doi.org/10.4135/9781412983648.

Assor, A., Kaplan, H., Kanat-Maymon, Y., \& Roth, G. (2005). Directly controlling teacher behaviors as predictors of poor motivation and engagement in girls and boys: the role of anger and anxiety. Learning and Instruction, 15(5), 397413. https://doi.org/10.1016/j.learninstruc.2005.07.008.

Bastalich, W., Franzway, S., Gill, J., Mills, J., \& Sharp, R. (2007). Disrupting masculinities: women engineers and engineering workplace culture. Australian Feminist Studies, 22(54), 385-400. https://doi.org/10.1080/0816464 0701578765.

Besterfield-Sacre, M., Moreno, M., Shuman, L. J., \& Atman, C. J. (2001). Gender and ethnicity differences in freshman engineering student attitudes: a crossinstitutional study. Journal of Engineering Education, 90(4), 477-490. https:// doi.org/10.1002/j.2168-9830.2001.tb00629.x.

Black, A. E., \& Deci, E. L. (2000). The effects of instructors' autonomy support and students' autonomous motivation on learning organic chemistry: a self- 
determination theory perspective. Science Education, 84(7), 740-756. https:// doi.org/10.1002/1098-237X(200011)84:6<740::AID-SCE4>3.0.CO;2-3.

Blanchard, C. M., Mask, L., Vallerand, R. J., Sablonnière, R. D., \& Provencher, P. (2007). Reciprocal relationships between contextual and situational motivation in a sport setting. Psychology of Sport and Exercise, 8(5), 854-873. https://doi.org/10.1016/j.psychsport.2007.03.004.

Boiché, J., Sarrazin, P., Grouzet, F., Pelletier, L., \& Chanal, J. (2008). Students' motivational profiles and achievement outcomes in physical education: a self-determination perspective. Journal of Educational Psychology, 100(3), 688701. https://doi.org/10.1037/0022-0663.100.3.688.

Boiché, J., \& Stephan, Y. (2014). Motivational profiles and achievement: a prospective study. Motivation and Emotion, 38(1), 79-92. https://doi.org/10.1 007/s11031-013-9361-6.

Brainard, S., \& Carlin, L. (1998). A six-year longitudinal study of undergraduate women in engineering and science. Journal of Engineering Education, 87(4), 369-375. https://doi.org/10.1002/j.2168-9830.1998.tb00367.x.

Braten, I., \& Olaussen, B. S. (2005). Profiling individual differences in student motivation: a longitudinal cluster-analytic study in different academic contexts. Contemporary Educational Psychology, 30(3), 359-396. https://doi. org/10.1016/j.cedpsych.2005.01.003.

Britner, S. L., \& Pajares, F. (2006). Sources of science self-efficacy beliefs of middle school students. Journal of Research in Science Teaching, 43(5), 485-499. https://doi.org/10.1002/tea.20131.

Carnegie Classification of Institutions of Higher Education (n.d.). Retrieved February 1, 2021, from http://carnegieclassifications.iu.edu/.

Cheon, S. H., \& Reeve, J. (2015). A classroom-based intervention to help teachers decrease students' amotivation. Contemporary Educational Psychology, 40, 99 111. https://doi.org/10.1016/j.cedpsych.2014.06.004.

Cheon, S. H., Reeve, J., Lee, Y., \& Lee, J. (2018). Why autonomy-supportive interventions work: explaining the professional development of teachers' motivating style. Teaching and Teacher Education, 69, 43-51. https://doi.org/1 0.1016/j.tate.2017.09.022.

Concannon, J. P., \& Barrow, L. H. (2009). A cross-sectional study of engineering students' self-efficacy by gender, ethnicity, year, and transfer status. Journal of Science Education and Technology, 18(2), 163-172. https://doi.org/10.1007/s1 0956-008-9141-3.

Concannon, J. P., \& Barrow, L. H. (2010). Men's and women's intentions to persist in undergraduate engineering degree programs. Journal of Science Education and Technology, 19(2), 133-145. https://doi.org/10.1007/s10956-009-9187-x.

Corpus, J. H., McClintic-Gilbert, M. S., \& Hayenga, A. O. (2009). Within-year changes in children's intrinsic and extrinsic motivational orientations: contextual predictors and academic outcomes. Contemporary Educational Psychology, 34(2), 154-166. https://doi.org/10.1016/j.cedpsych.2009.01.001.

Corpus, J. H., \& Wormington, S. V. (2014). Profiles of intrinsic and extrinsic motivations in elementary school: a longitudinal analysis. The Journal of Experimental Education, 82(4), 480-501. https://doi.org/10.1080/00220973.2 013.876225.

Csizer, K., \& Dornyei, Z. (2005). Language learners' motivational profiles and their motivated learning behavior. Language Learning, 55(4), 613-659. https://doi. org/10.1111/j.0023-8333.2005.00319.x.

De Bilde, J., Vansteenkiste, M., \& Lens, W. (2011). Understanding the association between future time perspective and self-regulated learning through the lens of self-determination theory. Learning and Instruction, 21(3), 332-344. https://doi.org/10.1016/j.learninstruc.2010.03.002.

DeBacker, T. K., \& Nelson, R. M. (2000). Motivation to learn science: differences related to gender, class type, and ability. The Journal of Educational Research, 93(4), 245-254. https://doi.org/10.1080/00220670009598713.

Deci, E. L., Koestner, R., \& Ryan, R. M. (1999). A meta-analytic review of experiments examining the effects of extrinsic rewards on intrinsic motivation. Psychological Bulletin, 125(6), 627-668. https://doi.org/10.1037/ 0033-2909.125.6.627.

Deci, E. L., \& Ryan, R. M. (2000). The "what" and "why" of goal pursuits: human needs and the self-determination of behavior. Psychological Inquiry, 11(4), 227-268. https://doi.org/10.1207/S15327965PLI1104_01.

Deci, E. L., Vallerand, R. J., Pelletier, L. G., \& Ryan, R. M. (1991). Motivation and education: the self-determination perspective. Educational Psychologist, 26(3\&4), 325-346. https://doi.org/10.1080/00461520.1991.9653137.

Diekman, A. B., \& Steinberg, M. (2013). Navigating social roles in pursuit of important goals: a communal goal congruity account of STEM pursuits. Social and Personality Psychology Compass, 7(7), 487-501. https://doi.org/1 $0.1111 /$ spc3.12042.
Dillon, A., \& Stolk, J. (2012). The students are unstable! Cluster analysis of motivation and early implications for educational research and practice. 2012 Frontiers in Education Conference Proceedings. https://doi.org/10.1109/FIE.2012.6462485.

Dillon, A., \& Stolk, J. D. (2014). Motivation-participation conflation: investigating response bias in intra-semester longitudinal class surveys, (pp. 1-5). 2014 Frontiers in Education Conference Proceedings. https://doi.org/10.1109/FIE.2 014.7044377

Dillon, A. E., Stolk, J. D., Zastavker, Y. V., \& Gross, M. D. (2016). Motivation is a twoway street: pedagogies employing discussion in addition to lecture display more positive student motivational response. 2016 ASEE Annual Conference \& Exposition.

Eccles, J., Wigfield, A., Harold, R. D., \& Blumenfield, P. (1993). Age and gender differences in children's self- and task perceptions during elementary school. Child Development, 64(3), 830-847. https://doi.org/10.1111/j.1467-8624.1993. tb02946.x.

Everitt, B. S., Landau, S., Leese, M., \& Stahl, D. (2011). Cluster analysis, (5th ed., ). Wiley. https://doi.org/10.1002/9780470977811.

Fong, C. J., Dillard, J. B., \& Hatcher, M. (2019). Teaching self-efficacy of graduate student instructors: exploring faculty motivation, perceptions of autonomy support, and undergraduate student engagement. International Journal of Education Research, 98, 91-105. https://doi.org/10.1016/j.ijer.2019.08.018.

Fortier, M. S., Vallerand, R. J., \& Guay, F. (1995). Academic motivation and school performance: toward a structural model. Contemporary Educational Psychology, 20, 257-274. https://doi.org/10.1006/ceps.1995.1017.

Gagné, M. (2003). The role of autonomy support and autonomy orientation in prosocial behavior engagement. Motivation and Emotion, 27(3), 199-223. https://doi.org/10.1023/A:1025007614869.

Garcia, T., \& Pintrich, P. R. (1996). The effects of autonomy on motivation and performance in the college classroom. Contemporary Educational Psychology, 21(4), 477-486. https://doi.org/10.1006/ceps.1996.0032.

Gasco, J., Goñi, A., \& Villarroel, J. D. (2014). Sex differences in mathematics motivation in 8th and 9th grade. Procedia - Social and Behavioral Sciences, 116(21), 1026-1031. https://doi.org/10.1016/j.sbspro.2014.01.340.

Gillet, N., Morin, A. J. S., \& Reeve, J. (2017). Stability, change, and implications of students' motivation profiles: a latent transition analysis. Contemporary Educational Psychology, 51, 222-239. https://doi.org/10.1016/j.cedpsych.2017. 08.006.

Greene, B. A., DeBacker, T. K., Ravindran, B., \& Krows, A. J. (1999). Goals, values, and beliefs as predictors of achievement and effort in high school mathematics classes. Sex Roles, 40(5), 421-458. https://doi.org/10.1023/A:101 8871610174

Greene, B. A., Miller, R. B., Crowson, H. M., Duke, B. L., \& Akey, K. L. (2004). Predicting high school students' cognitive engagement and achievement: contributions of classroom perceptions and motivation. Contemporary Educational Psychology, 29(4), 462-482. https://doi.org/10.1016/j.cedpsych.2 004.01.006.

Guay, F., Mageau, G. A., \& Vallerand, R. J. (2003). On the hierarchical structure of self-determined motivation: a test of top-down, bottom-up, reciprocal, and horizontal effects. Personality and Social Psychology Bulletin, 29(8), 992-1004. https://doi.org/10.1177/0146167203253297.

Guay, F., Vallerand, R. J., \& Blanchard, C. (2000). On the assessment of situational intrinsic and extrinsic motivation: the situational motivation scale (SIMS). Motivation and Emotion, 24(3), 175-213. https://doi.org/10.1023/A:100561422 8250.

Hackett, G., \& Betz, N. E. (1989). An exploration of the mathematics self-efficacy/ mathematics performance correspondence. Journal of Research in Mathematics Education, 20(3), 261-273. https://doi.org/10.2307/749515.

Hakan, K., \& Münire, E. (2014). Academic motivation: gender, domain and grade differences. Procedia - Social and Behavioral Sciences, 143(14), 708-715. https://doi.org/10.1016/j.sbspro.2014.07.469.

Hayenga, A. O., \& Corpus, J. H. (2010). Profiles of intrinsic and extrinsic motivations: a person-centered approach to motivation and achievement in middle school. Motivation and Emotion., 34(4), 371-383. https://doi.org/10.1 007/s11031-010-9181-x

Herman, G. L., Goldberg, D. E., Trenshaw, K. F., Somerville, M., \& Stolk, J. (2017). The intrinsic-motivation course design method. International Journal of Engineering Education, 33(2(A)), 558-574.

Heylen, C., Geraedts, K., Van Hemelrijck, I., Smet, M., Van Der Sloten, J., Creemers, C., \& Froyen, L. (2012). The background and motivation of first year engineering students at KU Leuven in relation to gender. Proceedings of the 40th SEFI Annual Conference. 
Hidi, S., \& Renninger, K. A. (2006). The four-phase model of interest development. Educational Psychologist, 41(2), 111-127. https://doi.org/10.1207/s1532 6985ep4102_4.

Hmelo-Silver, C. E. (2004). Problem-based learning: what and how do students learn? Educational Psychology Review, 16(3), 235-266. https://doi.org/10.1023/ B:EDPR.0000034022.16470.f3.

Hoffmann, L. (2002). Promoting girls' interest and achievement in physics classes for beginners. Learning and Instruction, 12(4), 447-465. https://doi.org/10.101 6/S0959-4752(01)00010-X.

Hutchison-Green, M. A., Follman, D. K., \& Bodner, G. M. (2008). Providing a voice: qualitative investigation of the impact of a first-year engineering experience on students' efficacy beliefs. Journal of Engineering Education, 97(2), 177-190. https://doi.org/10.1002/j.2168-9830.2008.tb00966.x.

Jacobs, J. E., Lanza, S., Osgood, D. W., Eccles, J. S., \& Wigfield, A. (2002). Changes in children's self-competence and values: gender and domain differences across grades one through twelve. Child Development, 71(2), 509-527. https:// doi.org/10.1111/1467-8624.00421.

Jang, H.-R. (2019). Teachers' intrinsic vs. extrinsic instructional goals predict their classroom motivating styles. Learning and Instruction, 60, 286-300. https://doi. org/10.1016/j.learninstruc.2017.11.001.

Jones, B. D., Paretti, M. C., Hein, S. F., \& Knott, T. W. (2010). An analysis of motivation constructs with first-year engineering students: relationships among expectancies, values, achievement, and career plans. Journal of Engineering Education, 99(4), 319-336. https://doi.org/10.1002/j.2168-9830.201 0.tb01066.x.

Kaplan, H., \& Madjar, N. (2017). The motivational outcomes of psychological need support among pre-service teachers: multicultural and self-determination perspectives. Frontiers in Education, 2(42), 1-14. https://doi.org/10.3389/ feduc.2017.00042.

Krapp, A. (2005). Basic needs and the development of interest and intrinsic motivational orientations. Learning and Instruction, 15(5), 381-395. https://doi. org/10.1016/j.learninstruc.2005.07.007.

Lavasani, M. G., Weisani, M., \& Ejei, J. (2011). The role of achievement goals, academic motivation, and learning strategies in statistics anxiety: testing a causal model. Procedia Social and Behavioral Sciences, 15, 1881-1885. https:// doi.org/10.1016/j.sbspro.2011.04.020

Lavigne, G., \& Vallerand, R. J. (2010). The dynamic processes of influence between contextual and situational motivation: a test of the hierarchical model in a science education setting. Journal of Applied Social Psychology, 40(9), $2343-$ 2359. https://doi.org/10.1111/j.1559-1816.2010.00661.x.

León, J., Núñez, J. L., \& Liew, J. (2015). Self-determination and STEM education: effects of autonomy, motivation, and self-regulated learning on high school math achievement. Learning and Individual Differences, 43, 156-163. https:// doi.org/10.1016/j.lindif.2015.08.017.

Liu, W. C., Wang, C. K. J., Tan, O. S., Koh, C., \& Ee, J. (2009). A self-determination approach to understanding students' motivation in project work. Learning and Individual Differences, 19(1), 139-145. https://doi.org/10.1016/j.lindif.2008.07.002.

Marra, R., Rodgers, K., Shen, D., \& Bogue, B. (2009). Women engineering students and self-efficacy: a multi-year, multi-institution study of women engineering student self-efficacy. Journal of Engineering Education, 98(1), 27-38. https:// doi.org/10.1002/J.2168-9830.2009.TB01003.X.

Meece, J. L., Glienke, B. B., \& Burg, S. (2006). Gender and motivation. Journal of School Psychology, 44(5), 351-373. https://doi.org/10.1016/j.jsp.2006.04.004

Meece, J. L., \& Painter, J. (2008). Gender, self-regulation, and motivation. In D. H. Schunk, \& B. J. Zimmerman (Eds.), Motivation and self-regulated learning: theory, research, and applications, (pp. 339-367). Lawrence Erlbaum Associates Publishers.

National Science and Technology Council (2011). The Federal Science, Technology, Engineering, and Mathematics (STEM) Education Portfolio, A Report from the Federal Inventory of STEM Education Fast-Track Action Committee. National Science and Technology Council (NSTC) Committee on STEM Education (COSTEM). Retrieved May 15, 2020. https://obamawhitehouse.archives.gov/ sites/default/files/microsites/ostp/costem_federal_stem_education_ portfolio_report.pdf

Nie, Y., \& Lau, S. (2010). Differential relations of constructivist and didactic instruction to students' cognition, motivation, and achievement. Learning and Instruction, 20(5), 411-423. https://doi.org/10.1016/j.learninstruc.2009.04.002.

Noels, K. A., Clement, R., \& Pelletier, L. G. (1999). Perceptions of teachers' communicative style and students' intrinsic and extrinsic motivation. The Modern Language Journal, 83(1), 23-34. https://doi.org/10.1111/0026-7902. 00003.
Paris, S. G., \& Paris, A. H. (2001). Classroom applications of research on selfregulated learning. Educational Psychologist, 36(2), 89-101. https://doi.org/1 $0.1207 /$ S15326985EP3602_4

Patall, E. A., Cooper, H., \& Robinson, J. C. (2008). The effects of choice on intrinsic motivation and related outcomes: a meta-analysis of research findings. Psychological Bulletin, 134(2), 270-300. https://doi.org/10.1037/0033-2 909.134.2.270.

Pelletier, L. G., Fortier, M. S., Vallerand, R. J., \& Brière, N. M. (2001). Associations among perceived autonomy support, forms of self-regulation, and persistence: a prospective study. Motivation and Emotion, 25(4), 279-306. https://doi.org/10.1023/A:1014805132406.

Pintrich, P., \& De Groot, E. V. (1990). Motivational and self-regulated learning components of classroom academic performance. Journal of Educational Psychology, 82(1), 33-40. https://doi.org/10.1037/0022-0663.82.1.33.

Pintrich, P. R. (1999). The role of motivation in promoting and sustaining selfregulated learning. International Journal of Educational Research, 31(6), 459470. https://doi.org/10.1016/S0883-0355(99)00015-4.

Ratelle, C. F., Baldwin, M. W., \& Vallerand, R. J. (2005). On the cued activation of situational motivation. Journal of Experimental Social Psychology, 41(5), 482487. https://doi.org/10.1016/j.jesp.2004.10.001

Ratelle, C. F., Guay, F., Vallerand, R. J., Larose, S., \& Senécal, C. (2007). Autonomous, controlled, and amotivated types of academic motivation: a person-oriented analysis. Journal of Educational Psychology, 99(4), 734-746. https://doi.org/10.1 037/0022-0663.99.4.734

Reeve, J. (2009). Why teachers adopt a controlling motivating style toward students and how they can become more autonomy supportive. Educational Psychologist, 44(3), 159-175. https://doi.org/10.1080/00461520903028990.

Reeve, J., Jang, H., Carrell, D., Jeon, S., \& Barch, J. (2004). Enhancing students' engagement by increasing autonomy support. Motivation and Emotion, 28(2), 147-169.

Rotgans, J. I., \& Schmidt, H. G. (2011). Situational interest and academic achievement in the active-learning classroom. Learning and Instruction, 21(1), 58-67. https://doi.org/10.1016/j.learninstruc.2009.11.001.

Roth, G., Assor, A., Kanat-Maymon, Y., \& Kaplan, H. (2007). Autonomous motivation for teaching: how self-determined teaching may lead to selfdetermined learning. Journal of Educational Psychology, 99(4), 761-774. https://doi.org/10.1037/0022-0663.99.4.761.

Ruzek, E. A., Hafen, C. A., Allen, J. P., Gregory, A., Mikami, A. Y., \& Pianta, R. C. (2016). How teacher emotional support motivates students: the mediating roles of perceived peer relatedness, autonomy support, and competence. Learning and Instruction, 42, 95-103. https://doi.org/10.1016/j.learninstruc.2016.01.004.

Ryan, R. M., \& Deci, E. L. (2000). Self-determination theory and the facilitation of intrinsic motivation, social development, and well-being. American Psychologist, 55(1), 68-78. https://doi.org/10.1037/0003-066X.55.1.68.

Schunk, D. H., \& Pajares, F. (2002). The development of academic self-efficacy. In A. Wigfield, \& J. S. Ecclesf (Eds.), Development of achievement motivation, (pp. 15-31). Academic Press. https://doi.org/10.1016/B978-012750053-9/50003-6.

Skinner, E. A., \& Belmont, M. J. (1993). Motivation in the classroom: reciprocal effects of teacher behavior and student engagement across the school year. Journal of Educational Psychology., 85(4), 571-581. https://doi.org/10.1037/ 0022-0663.85.4.571.

Stefanou, C., Stolk, J. D., Prince, M., Chen, J. C., \& Lord, S. M. (2013). Self-regulation and autonomy in problem- and project-based learning environments. Active Learning in Higher Education, 14(2), 109-122. https://doi.org/10.1177/1469787413481132.

Stolk, J., \& Harari, J. (2014). Student motivations as predictors of high-level cognitions in project-based classrooms. Active Learning in Higher Education, 15(3), 231-247. https://doi.org/10.1177/1469787414554873.

Stolk, J. D., \& Martello, R. (2015). Can disciplinary integration promote students' lifelong learning attitudes and skills in project-based engineering courses? International Journal of Engineering Education, 31(1(B)), 434-449.

Stolk, J. D., Zastavker, Y. V., \& Gross, M. D. (2018). Gender, motivation, and pedagogy in the STEM classroom: a quantitative characterization. 2018 ASEE Annual Conference \& Exposition.

Stolk, J. D., Jacobs, J., Girard, C., \& Pudvan, L. (2018). Learners' needs satisfaction, classroom climate, and situational motivations: evaluating self-determination theory in an engineering context (pp. 1-5). 2018 IEEE Frontiers in Education Conference. https://doi.org/10.1109/FIE.2018.8658880.

Stupnisky, R. H., BrckaLorenz, A., Yuhas, B., \& Guay, F. (2018). Faculty members' motivation for teaching and best practices: testing a model based on selfdetermination theory across institution types. Contemporary Educational Psychology, 53, 15-26. https://doi.org/10.1016/j.cedpsych.2018.01.004. 
Tonso, K. L. (2006). Student engineers and engineer identity: campus engineer identities as figured world. Cultural Studies of Science Education, 1(2), 273-307. https://doi.org/10.1007/s11422-005-9009-2.

Trautwein, U., \& Ludtke, O. (2009). Predicting homework motivation and homework effort in six school subjects: the role of person and family characteristics, classroom factors, and school track. Learning and Instruction, 19(3), 243-258. https://doi.org/10.1016/j.learninstruc.2008.05.001.

Trenshaw, K. F., Alonso, R. A. R., Earl, K. E., \& Herman, G. L. (2014). Events that promote engineering students' intrinsic motivation to learn. 2014 ASEE Annual Conference \& Exposition.

U.S. Department of Education (2018). Digest of Education Statistics: 2018. Institute of Education Sciences, National Center for Education Statistics. Retrieved June 1, 2020. https://nces.ed.gov/programs/digest/d18/.

Vallerand, R. J. (2000). Deci and Ryan's self-determination theory: a view from the hierarchical model of intrinsic and extrinsic motivation. Psychological Inquiry, 11(4), 312-318

Vallerand, R. J. (2001). A hierarchical model of intrinsic and extrinsic motivation in sport and exercise. In G. C. Roberts (Ed.), Advances in motivation in sport and exercise, (pp. 263-319). Human Kinetics.

Vallerand, R. J., \& Bissonnette, R. (1992). Intrinsic, extrinsic, and amotivational styles as predictors of behavior: a prospective study. Journal of Personality, 60(3), 599-620. https://doi.org/10.1111/j.1467-6494.1992.tb00922.x.

Vallerand, R. J., Pelletier, L. G., Blais, M. R., Briere, N. M., Senecal, C., \& Vallieres, E. F. (1992). The academic motivation scale: a measure of intrinsic, extrinsic, and amotivation in education. Educational and Psychological Measurement, 52(4), 1003-1017. https://doi.org/10.1177/0013164492052004025.

Vansteenkiste, M., Aelterman, N., De Muynck, G.-J., Haerens, L., Patall, E., \& Reeve, J. (2018). Fostering personal meaning and self-relevance: A self-determination theory perspective on internalization. The Journal of Experimental Education, 86(1), 30-49. https://doi.org/10.1080/00220973.2017.1381067.

Vansteenkiste, M., Lens, W., \& Deci, E. L. (2006). Intrinsic versus extrinsic goal contents in self-determination theory: another look at the quality of academic motivation. Educational Psychologist, 41(1), 19-31. https://doi.org/1 0.1207/s15326985ep4101_4.

Vansteenkiste, M., Sierens, E., Soenens, B., Luyckx, K., \& Lens, W. (2009). Motivational profiles from a self-determination perspective: the quality of motivation matters. Journal of Educational Psychology, 101(3), 671-688. https://doi.org/10.1037/a0015083.

Vansteenkiste, M., Simons, J., Lens, W., Soenens, B., \& Matos, L. (2005). Examining the motivational impact of intrinsic versus extrinsic goal framing and autonomy-supportive versus internally controlling communication style on early adolescents' academic achievement. Child Development, 76(2), 483-501. https://doi.org/10.1111/j.1467-8624.2005.00858.x.

Vecchione, M., Alessandri, G., \& Marsicano, G. (2014). Academic motivation predicts educational attainment: does gender make a difference? Learning and Individual Differences, 32, 124-131. https://doi.org/10.1016/j. lindif.2014.01.003.

Vogt, C. M. (2007). A social cognitive construct validation: determining women's and men's success in engineering programs. The Journal of Higher Education, 78(3), 337-364. https://doi.org/10.1080/00221546.2007.11772319.

Walker, C. O., Greene, B. A., \& Mansell, R. A. (2006). Identification with academics, intrinsic/extrinsic motivation, and self-efficacy as predictors of cognitive engagement. Learning and Individual Differences, 16(1), 1-12. https://doi.org/1 0.1016/j.lindif.2005.06.004.

Wang, M., \& Eccles, J. S. (2013). School context, achievement motivation, and academic engagement: a longitudinal study of school engagement using a multidimensional perspective. Learning and Instruction, 28, 12-23. https://doi. org/10.1016/j.learninstruc.2013.04.002.

Weisgram, E. S., \& Bigler, R. S. (2006). Girls and science careers: the role of altruistic values and attitudes about scientific tasks. Journal of Applied Developmental Psychology, 27(4), 326-348. https://doi.org/10.1016/j.appdev.2 006.04.004.

Wigfield, A., Battle, A., Keller, L. B., \& Eccles, J. S. (2002). Sex differences in motivation, self-concept, career aspiration, and career choice: implications for cognitive development. In A. McGillicuddy-De Lisi, \& R. De Lisi (Eds.), Advances in applied developmental psychology, Biology, society, and behavior: the development of sex differences in cognition (vol. 21, pp. 93-124). Ablex Publishing

Wigfield, A., \& Cambria, J. (2010). Students' achievement values, goal orientations, and interest: definitions, development, and relations to achievement outcomes. Developmental Review, 30(1), 1-35. https://doi.org/10.1016/j.dr.2 009.12.001.
Wijnia, L., Loyens, S. M. M., \& Derous, E. (2011). Investigating effects of problembased versus lecture-based learning environments on student motivation. Contemporary Educational Psychology, 36(2), 101-113. https://doi.org/10.1016/ j.cedpsych.2010.11.003.

Young, M. R. (2005). The motivational effects of the classroom environment in facilitating self-regulated learning. Journal of Marketing Education, 27(1), 2540. https://doi.org/10.1177/0273475304273346.

Zimmerman, B. J., \& Martinez-Pons, M. (1990). Student differences in selfregulated learning: relating grade, sex, and giftedness to self-efficacy and strategy use. Journal of Educational Psychology, 82(1), 51-59. https://doi.org/1 0.1037/0022-0663.82.1.51.

\section{Publisher's Note}

Springer Nature remains neutral with regard to jurisdictional claims in published maps and institutional affiliations.

\section{Submit your manuscript to a SpringerOpen ${ }^{\circ}$ journal and benefit from:}

- Convenient online submission

- Rigorous peer review

- Open access: articles freely available online

High visibility within the field

- Retaining the copyright to your article

Submit your next manuscript at $\boldsymbol{\nabla}$ springeropen.com 